\title{
Fundamentals News, Global Liquidity and Macroprudential Policy *
}

\author{
JAVIER BIANCHI \\ Chenxin LiU \\ Minneapolis Fed \& NBER \\ University of Wisconsin \\ ENRIQUe G. MENDOZA \\ University of Pennsylvania, NBER \& PIER
}

December 5, 2015

\begin{abstract}
We study optimal macroprudential policy in a model in which unconventional shocks, in the form of news about future fundamentals and regime changes in world interest rates, interact with collateral constraints in driving the dynamics of financial crises. These shocks strengthen incentives to borrow in good times (i.e. when "good news" about future fundamentals coincide with a low-world-interest-rate regime), thereby increasing vulnerability to crises and enlarging the pecuniary externality due to the collateral constraints. Quantitatively, an optimal schedule of macroprudential debt taxes can lower the frequency and magnitude of financial crises, but the policy is complex because it features significant variation across interest-rate regimes and news realizations.
\end{abstract}

KEYwords: Financial crises, macroprudential policy, systemic risk, global liquidity, news shocks

JEL Classification Codes: D62, E32, E44, F32, F41

* This paper was prepared for the 2015 International Seminar on Macroeconomics. We would like to thank our discussant, Damiano Sandri, and conference participants for helpful comments and suggestions. We are grateful for the support of the National Science Foundation under awards 1325122 (Mendoza) and 1324395 (Bianchi). Mendoza acknowledges also the support of the Representative Office for the Americas of the Bank for International Settlements, where he was a visitor while working on part of this project. An earlier version of this paper circulated under the title "Phases of Global Liquidity, Fundamentals News and the Design of Macroprudential Policy." 


\section{Introduction}

The goal of macroprudential policy is clear: hamper excessive credit growth in periods of expansion in order to lower the frequency and magnitude of financial crises. How to optimally design and implement this policy is much less clear. One major challenge is the development of a wellestablished quantitative framework that can be used to study endogenous financial amplification mechanisms capable of producing infrequent financial crises with realistic features, and to evaluate the effectiveness of alternative macroprudential policy strategies.

A class of models that has made progress in tackling these issues makes use of the Fisherian debt-deflation mechanism to amplify the effects of exogenous shocks in periods of financial distress, and thus generate nonlinear crisis dynamics. In models of this class, the market failure that justifies the use of macroprudential policy is a pecuniary externality that is ubiquitous in credit markets, because goods or assets used as collateral are valued at market prices: Private agents in a decentralized equilibrium do not internalize the negative effects of individual borrowing decisions made in "good times" on collateral prices in "bad times," when the debt-deflation mechanism induces large declines in relative prices. As a result, private agents borrow too much, relative to what is socially optimal, and leave the economy vulnerable to financial crises.

Existing quantitative studies in this literature have shown that collateral constraints can produce substantial amplification and asymmetry in response to standard-size shocks hitting the typical driving forces of business cycles, such as TFP and terms-of-trade shocks (e.g. Mendoza, 2010), and have also demonstrated how these models can be used to study the characteristics and effectiveness of various financial policies, including macroprudential policy. ${ }^{1}$ Most of the models developed to date (e.g. Bianchi, 2011), however, study macroprudential policy in environments with conventional shocks, usually TFP or interest-rate shocks that follow symmetric probabilistic processes known to agents. ${ }^{2}$ As a result, two potentially important sources of financial volatility that deviate from this treatment, noisy news about future economic fundamentals and regime shifts in global liquidity, are still absent from the analysis of macroprudential policy. This is in sharp contrast with empirical studies of credit cycles and financial crises, which suggest that factors like these are important determinants of credit dynamics and their interaction with the real economy (e.g., Calvo et al. (1996), Shin (2013), Bruno and Shin (2014), Mendoza and Terrones (2012), Borio (2014), Reinhart and Rogoff (2014), Schularick and Taylor (2012)).

This paper aims to fill these gaps by introducing both news shocks and regime switches in

\footnotetext{
${ }^{1}$ Some of these studies include Bianchi (2011), Benigno et al. (2013,2014), Bianchi and Mendoza (2010 2013), Jeanne and Korinek (2010), Bengui and Bianchi (2014), (see the literature reviews by Galati and Moessner (2013), Galati and Moessner (2014) and Korinek and Mendoza (2014)). See also Schmitt-Grohé and Uribe (2013) and Farhi and Werning (2012) for studies on macroprudential policy motivated by aggregate demand externalities.

${ }^{2}$ Two exceptions are Bianchi et al. (2012), who examine macroprudential policy in the setup of Boz and Mendoza (2014), in which informational frictions lead to endogenous booms in asset valuation, and Flemming, L'Huillier, and Piguillem (2015) who study shifts in the perception of future income realizations due to persistent growth shocks.
} 
global liquidity into a Fisherian model of macroprudential policy. Noisy, but informative, news about future income shocks are introduced as a driving force of credit cycles following the recent macro literature on news and economic fluctuations. ${ }^{3}$ For example, in the years leading to the recent European crisis, the prolonged boom of Southern Europe could be viewed as related to anticipated benefits from joining the EU. Shifts in global liquidity are introduced as a regimeswitching process in the evolution of world interest rates or leverage limits supported by world capital markets. Calvo et al. (1996) and Shin (2013) document the importance of fluctuations in global capital market conditions and world interest rates in driving capital inflows and domestic credit in emerging economies.

The paper presents both theoretical and quantitative findings that highlight the effects of news about fundamentals and global liquidity shifts on the design of optimal macroprudential policy. In addition, we provide a Matlab toolkit that uses global, non-linear solution methods to solve Fisherian models in which a collateral constraint is linked to factor and goods prices, and to evaluate macroprudential policy. These algorithms can be used to solve for the optimal policy and assessing its effects, and also for evaluating the effects of alternative simple policy rules and comparing their performance with the optimal policy.

The analysis shows that both news about fundamentals and regime-switches in world financial conditions are important driving forces of financial crisis dynamics. Macroprudential policy is implemented as a state-contingent tax on debt that yields the same allocations and prices supported by a constrained-efficient social planner who internalizes the pecuniary externality. This optimal debt tax is an effective tool for reducing the likelihood and magnitude of financial crises, but it requires significant variation across capital-markets regimes and news realizations. When the precision of news rises, crises become more likely as agents can forecast better future fluctuations. At the same time, however, crises become more severe as agents accumulate less precautionary savings during good times. Overall, the need for macroprudential policy is reduced as the precision of news rises. In fact, as the precision of news increase, there are smaller welfare gains and lower average debt taxes associated to macroprudential policy.

The rest of the paper is organized as follows. Section 2 describes the decentralized equilibrium of the model without policy intervention. Section 3 examines the problem solved by the financial regulator, the role of macroprudential policy, and the decentralization of optimal macroprudential policy as taxes on debt. Section 4 examines the quantitative predictions of the model. Section 5 provides conclusions. Two appendices provide mathematical details and describe the solution toolkit.

\footnotetext{
${ }^{3}$ See, for example, Beaudry and Portier (2006), Schmitt-Grohé and Uribe (2012) Jaimovich and Rebelo (2009), Christiano et al. (2010), Blanchard, L'Huillier, and Lorenzoni (2013).
} 


\section{Model}

The model is in the vein of the two-sector framework of Sudden Stops proposed by Mendoza (2002) and used to study optimal macroprudential policy by Bianchi (2011). We introduce noisy news about future income and regime-switches in world interest rates into that framework.

\subsection{Representative Household's problem}

Consider a small open economy inhabited by a representative household who consumes tradable and nontradable goods, denoted $c^{T}$ and $c^{N}$ respectively. Preferences are given by a standard intertemporal utility function with constant relative risk aversion (CRRA):

$$
\mathbb{E}_{0} \sum_{t=0}^{\infty} \beta^{t} u(c), \quad u(c)=\frac{c^{1-\gamma}}{1-\gamma}
$$

In this expression, $\mathbb{E}(\cdot)$ is the expectation operator, $\beta$ is the discount factor, and $\gamma$ is the coefficient of relative risk aversion. Note that the CRRA functional form is not critical, what is critical is that the period utility function $u(\cdot)$ be a concave, twice-continuously differentiable function that satisfies the Inada condition. The consumption basket $c$ is a CES aggregator with elasticity of substitution $1 /(\eta+1)$ between $c^{T}$ and $c^{N}$, given by:

$$
c=\left[\omega\left(c^{T}\right)^{-\eta}+(1-\omega)\left(c^{N}\right)^{-\eta}\right]^{-\frac{1}{\eta}}, \eta>1, \omega \in(0,1)
$$

Normalizing the price of tradable goods to 1 and denoting the relative price of nontradables by $p^{N}$, the agent's budget constraint is:

$$
q_{t} b_{t+1}+c_{t}^{T}+p_{t}^{N} c_{t}^{N}=b_{t}+y_{t}^{T}+p_{t}^{N} y_{t}^{N}
$$

The representative agent has access to a global market of one-period, non-state-contingent bonds denominated in units of tradable goods sold at a price $q_{t}=1 / R_{t}$, where $R_{t}$ is the exogenous gross world real interest rate. The stochastic process of the interest rate exhibits regime switches that characterize periods of high and low global liquidity, as explained below. The agent begins the

period with bond holdings $b_{t}$ and chooses $b_{t+1}$, and collects a stochastic endowment of tradables 
$y_{t}^{T}$ and a fixed endowment of non-tradables $y_{t}^{N}$. The stochastic process of $y_{t}^{T}$ follows a standard Markov process to be specified later, and is influenced by the arrival of noisy news, along the lines of the literature on news and business cycles (see Beaudry and Portier (2014) for a recent survey). In particular, every period the representative agent receives noisy news that relates to the future evolution of $y_{t}^{T}$.

The representative agent faces a credit constraint that limits its debt not to exceed a fraction $\kappa$ of its total income in units of tradables:

$$
q_{t} b_{t+1} \geq-\kappa\left(y_{t}^{T}+p_{t}^{N} y_{t}^{N}\right)
$$

This collateral constraint can be viewed as resulting from enforcement or institutional frictions by which lenders are only able to harness a fraction $\kappa$ of a borrower's income in case of non-repayment, or it can also be thought of as capturing observed practices in credit markets, such as the scoring alogorithms used in household credit.

The separation between tradables and nontradables in the credit constraint is intended to capture the "liability dollarization" phenomenon typical of emerging economies: Foreign liabilities are generally contracted in hard currencies, which represent tradable goods, but are backed up by the income generated in both tradables and nontradables sector of the economy. The contracting of the liabilities often occurs via bank intermediation, with domestic banking systems borrowing abroad in hard currencies and lending at home in the domestic currency, but more recently direct borrowing in corporate bonds has also surged (see Shin, 2013, Bruno and Shin (2014)).

The representative agent chooses optimally the stochastic processes $\left\{c_{t}^{T}, c_{t}^{N}, b_{t+1}\right\}_{t \geq 0}$ to $\max -$ imize expected lifetime utility (1) subject to sequences of budget constraints (3) and credit constraints (4), taking $b_{0}$ and $\left\{p_{t}^{N}\right\}_{t \geq 0}$ as given. This maximization problem yields the following first-order conditions:

$$
\begin{gathered}
\lambda_{t}=u_{T}(t) \\
p_{t}^{N}=\left(\frac{1-\omega}{\omega}\right)\left(\frac{c_{t}^{T}}{c_{t}^{N}}\right)^{\eta+1} \\
\lambda_{t}=\frac{\beta}{q_{t}} \mathbb{E}_{t}\left[\lambda_{t+1}+\mu_{t}\right] \\
q_{t} b_{t+1}+\kappa\left(y_{t}^{T}+p_{t}^{N} y_{t}^{N}\right) \geq 0, \quad \text { with equality if } \mu_{t}>0,
\end{gathered}
$$

where $u_{T}$ denotes the partial derivative of the utility function with respect to $c_{t}^{T}, \lambda_{t}$ is the Lagrange multiplier on the budget constraint, and $\mu_{t}$ is the Lagrange multiplier on the credit constraint. 
Notice that regime switches in the world interest rate affect borrowing incentives via their effect on the marginal cost of borrowing in the right-hand-side of the Euler equation (7), and that news about future values of $y_{t}^{T}$ alter both incentives to borrow at $t$ and expectations of future borrowing capacity. Hence, changes in global liquidity and news shocks affect the volatility of capital flows and the economy's vulnerability to financial crises.

\subsection{Competitive Equilibrium}

The competitive equilibrium is given by sequences of allocations $\left\{c_{t}^{T}, c_{t}^{N}, b_{t+1}\right\}_{t \geq 0}$ and prices $\left\{p_{t}^{N}\right\}_{t \geq 0}$ such that: (a) the representative agent maximizes utility subject to the budget and collateral constraints taking prices as given, and (b) the market-clearing conditions of the market of nontradable goods holds: $c_{t}^{N}=y_{t}^{N}$. This condition, together with the agents' budget constraint, implies that the resource constraint of the small open economy's tradables sector also holds: $c_{t}^{T}=y_{t}^{T}-q_{t} b_{t+1}+b_{t}$.

\subsection{Fundamentals News and Global Liquidity Regimes}

We model news about fundamentals as noisy signals of future realizations of $y^{T}$ following the specification proposed by Durdu et al. (2013). The probability of a signal conditional on an income realization satisfies the following condition:

$$
p\left(s_{t}=i \mid y_{t+1}^{T}=l\right)= \begin{cases}\theta & \text { if } i=l \\ \frac{1-\theta}{N-1} & \text { if } i \neq l\end{cases}
$$

where $s_{t}$ is the signal that agents receive at date $t, N$ is the number of possible realizations of $y_{t}^{T}$ at any date $t$, and $\theta$ is the signal precision parameter. When $\theta=\frac{1}{N}$, the signals are completely uninformative, because $p\left(s_{t}=i \mid y_{t+1}^{T}=l\right)$ simply assigns a uniform probability of $1 / N$ to all values the signal can take, regardless of the value of $y_{t+1}^{T}$. Hence, news do not add any information useful to alter the expectations about $y_{t+1}^{T}$ that are formed using the probabilistic process of $y^{T}$ alone. When $\theta=1$, the signals have perfect precision: News allow the agent to perfectly anticipate the value of $y_{t+1}^{T}$ (i.e. a given value of $y_{t+1}^{T}=l$ will be expected to occur with perfect certainty when the signal $s_{t}=l$ is observed).

The conditional forecast probability of next period's tradables income, conditional on a par- 
ticular observed pair of current income and news signal, is derived following Bayes' theorem:

$$
p\left(y_{t+1}^{T}=l \mid s_{t}=i, y_{t}^{T}=j\right)=\frac{p\left(s_{t}=i \mid y_{t+1}^{T}=l\right) p\left(y_{t+1}^{T}=l \mid y_{t}^{T}=j\right)}{\sum_{n} p\left(s_{t}=i \mid y_{t+1}^{T}=n\right) p\left(y_{t+1}^{T}=n \mid y_{t}^{T}=j\right)}
$$

The Markov chain for the joint evolution of $y^{T}$ and $s$ is then given by:

$$
\begin{aligned}
\Pi\left(y_{t+1}^{T}, s_{t+1}, y_{t}^{T}, s_{t}\right) & \equiv p\left(s_{t+1}=k, y_{t+1}^{T}=l \mid s_{t}=i, y_{t}^{T}=j\right) \\
& =p\left(y_{t+1}^{T}=l \mid s_{t}=i, y_{t}^{T}=j\right) \sum_{m}\left[p\left(y_{t+2}^{T}=m \mid y_{t+1}^{T}=l\right) p\left(s_{t+1}=k \mid y_{t+2}^{T}=m\right)\right]
\end{aligned}
$$

Expectations in the optimization problem solved by the representative agent are taken using $\Pi(\cdot)$ instead of using just the Markov transition probability matrix of $y_{t}^{T}$ to $y_{t+1}^{T}$. Notice that $\Pi(\cdot)$ is a conditional probability that combines the information provided by the date-t signal and income realization about the likelihood of a particular date- $t+1$ income realization with the associated expectation of a date-t +1 signal for that income realization. This is because agents know that signals themselves are stochastic, and hence form rational expectations about their future evolution. ${ }^{4}$

Fluctuations in global liquidity across high- and low-liquidity regimes are modeled as regime switches in the world real interest rate, using a standard two-point, regime-switching process with regimes $R^{h}$ (low global liquidity) and $R^{l}$ (high global liquidity) with $R^{h}>R^{l}$. The continuation transition probabilities are denoted $F_{h h} \equiv p\left(R_{t+1}=R^{h} \mid R_{t}=R^{h}\right)$ and $F_{l l} \equiv p\left(R_{t+1}=R^{l} \mid R_{t}=\right.$ $R^{l}$ ), and the switching probabilities are simply $F_{h l}=1-F_{h h}$ and $F_{l h}=1-F_{l l}$. The long-run probabilities of each regime are $\Pi^{h}=F_{l h} /\left(F_{l h}+F_{h l}\right)$ and $\Pi^{l}=F_{h l} /\left(F_{l h}+F_{h l}\right)$ respectively, and the corresponding mean durations are $1 / F_{h l}$ and $1 / F_{l h}$. The long-run unconditional mean, variance, and first-order autocorrelation of $R$ are given by the standard formulae:

$$
\begin{aligned}
E[R] & =\left(F_{l h} R^{h}+F_{h l} R^{l}\right) /\left(F_{l h}+F_{h l}\right) \\
\sigma^{2}(R) & =\Pi^{h}\left(R^{h}\right)^{2}+\Pi^{l}\left(R^{l}\right)^{2}-(E[R])^{2} \\
\rho(R) & =F_{l l}-F_{h l}=F_{h h}-F_{l h}
\end{aligned}
$$

\footnotetext{
${ }^{4}$ Notice that $\theta=1$ does not remove income uncertainty completely. The realization of $y_{t+1}^{T}$ is anticipated at date $\mathrm{t}$ with certainty, but since signals remain stochastic, agents still form expectations of income for $\mathrm{t}+2$ and beyond based on expectations of the evolution of the signals.
} 
We also studied an alternative modeling global liquidity regimes as changes in $\kappa$, instead of changes in $R$. The quantitative implications of following this approach are discussed later in the paper.

\section{Planner's Problem \& Macroprudential Policy}

Following Bianchi (2011), we study a constrained planner's problem in which a planner (or financial regulator) chooses directly the economy's holdings of non-state contingent bonds subject to the credit constraint, and lets all other markets clear competitively. The crucial difference is that, in contrast with private agents, the planner internalizes how borrowing decisions affect consumption, which in turn affect the equilibrium price of non-tradables and the tightness of the credit constraint (i.e. the "borrowing capacity").

The planner's dynamic programming problem in recursive form, following the standard convention of denoting with a prime variables dated $t+1$, is defined as follows:

$$
V(b, z)=\max _{p^{N}, c^{T}, c^{N}, b^{\prime}}\left[u\left(\left[\omega\left(c^{T}\right)^{-\eta}+(1-\omega)\left(c^{N}\right)^{-\eta}\right]^{-\frac{1}{\eta}}\right)+\beta \mathbb{E} V\left(b^{\prime}, z^{\prime}\right)\right]
$$

subject to

$$
\begin{gathered}
c^{T}+q b^{\prime}=b+y^{T} \\
c^{N}=y^{N} \\
q b^{\prime} \geq-\kappa\left(y^{T}+p^{N} y^{N}\right) \\
p^{N}=\left(\frac{1-\omega}{\omega}\right)\left(\frac{c^{T}}{c^{N}}\right)^{\eta+1}
\end{gathered}
$$

The state variables are the current bond holdings, $b$, and the realizations of the exogenous shocks denoted as $z=\left(y^{T}, s, q\right)$. The constraints faced by the planner are: the resource constraint for tradable goods (equation (16)), the market-clearing condition in the nontradable goods market (equation (17)), the credit constraint (equation (18)), and the condition that characterizes optimal sectoral consumption allocations (equation (19)).

As shown in Appendix 1, the first-order conditions of the above problem (in sequential form) 
can be reduced to the following two expressions:

$$
\begin{aligned}
\lambda_{t} & =u_{T}(t)+\mu_{t} \psi_{t} \\
\lambda_{t} & =\frac{\beta}{q_{t}} \mathbb{E}_{t}\left[\lambda_{t+1}+\mu_{t}\right]
\end{aligned}
$$

where $\lambda_{t}$ and $\mu_{t}$ denote the Lagrange multipliers on the resource constraint and credit constraint respectively, and the term $\psi_{t} \equiv \kappa\left[\frac{1-\omega}{\omega}(1+\eta) \frac{c^{T}}{y^{N}}\right]$ captures the effect of an additional unit of tradables consumption on the borrowing capacity via general equilibrium effects on the price of nontradables, which affects the value of collateral. ${ }^{5}$ In turn, the term $\mu_{t} \psi_{t}$ reflects the fact that, when the credit constraint binds, the social marginal benefit from consumption of tradable goods includes the gains resulting from how changes in consumption help relax the credit constraint, in addition to the marginal utility of tradables consumption.

From a macroprudential perspective, the focus is on how to affect credit allocations in "good times" because of what those allocations can cause in "bad times." Accordingly, the scenario of interest is one in which the credit constraint is not binding at date $t$ (i.e. $\mu_{t}=0$ ) but may be binding at $t+1\left(E_{t}\left[\mu_{t+1}\right]>0\right)$. In this scenario, the planner's Euler equation takes this form:

$$
u_{T}(t)=\frac{\beta}{q_{t}} \mathbb{E}_{t}\left[u_{T}(t+1)+\mu_{t+1} \psi_{t+1}\right]
$$

Comparing this condition with the household's Euler equation for bonds shows that, as in Bianchi (2011), there is a wedge between the private and social marginal cost of borrowing, given by the term $\mu_{t+1} \psi_{t+1}$. In particular, when the credit constraint is expected to bind, the planner faces a strictly higher marginal cost of borrowing than the representative agent. This is a pecuniary externality, because it results from the fact that the planner makes borrowing choices at $t$ taking into account that the credit constraint could bind at $t+1$, and if it does the Fisherian debt-deflation mechanism will cause a collapse of the relative price of nontradables that will shrink borrowing capacity. The representative agent takes prices as given at all times, and thus does not internalize these effects.

News about domestic fundamentals and regime-switching of global liquidity have important effects on the pecuniary externality. "Good news" at $t$ about future income lead to higher consumption, and since that increase in income has not been realized yet, this leads to an increase in borrowing which makes the economy more vulnerable to hitting the credit constraint. On the

\footnotetext{
${ }^{5}$ The term in square brackets measures how total income in units of tradables (i.e. the value of collateral) changes with the choice of $b_{t+1}$, because this choice alters consumption of tradables and the relative price of nontradables.
} 
other hand, by increasing expected future income, the good news also increase on expectation the future borrowing capacity and at the same time reduce future borrowing needs. As a result of these effect, we will show below that good news generate a larger fat tail in the distribution of the economy's bond holdings (i.e. higher mass at higher debt levels), by generating an increase in external borrowing and exposing the economy to events in which good news turn out not be realized ex post. ${ }^{6}$ The regime shifts in global liquidity affect the pecuniary externality because lower interest rates make borrowing cheaper, and lead the economy to take on more debt. A sudden increase in the interest rate, or an adverse income shock, can lead to a decline in consumption, which in turn makes the credit constraint tighter and leads to a sharp reduction in capital flows.

The constrained-efficient allocations and prices that solve the planner's problem can be decentralized as a competitive equilibrium using various policy instruments, including taxes on debt, loan-to-value ratios, capital requirements or reserve requirements (see Bianchi (2011), Stein (2012)). Since the market failure is a pecuniary externality, the natural instrument to consider is a standard tax on the cost of the good associated with the externality, in this case the cost of borrowing. Taxing the cost of borrowing at a rate $\tau_{t}$, the cost of purchasing bonds in the budget constraint becomes $\left[q_{t} /\left(1+\tau_{t}\right)\right] b_{t+1}$. The optimal macroprudential tax can then be derived as the value of $\tau_{t}$, which varies across time and states of nature, that equates the Euler equations of bonds of the social planner and the decentralized equilibrium with the tax. Hence, the tax induces private agents to face the social marginal cost of borrowing in the states in which this cost differs from the private cost in the absence of macroprudential policy (assuming in addition that the revenue of the tax is rebated to the household as a lump-sum transfer). ${ }^{7}$ When $\mu_{t}=0$, the optimal macro-prudential tax can be expressed as follows:

$$
\tau_{t}=\frac{\mathbb{E}_{t}\left[\mu_{t+1} \psi_{t+1}\right]}{\mathbb{E}_{t}\left[u_{T}(t+1)\right]}
$$

Notice that this tax captures the pecuniary externality, which reflects the possibility of a financial crisis the following period, as analyzed above. ${ }^{8}$

\footnotetext{
${ }^{6}$ Flemming et al. (2015) provide a theoretical characterization of how shifts in the distribution of future income affect borrowing for the planner in a three-period model with unitary elasticity of substitution across $c^{T}$ and $c^{N}$, and quantitatively analyze this issue in a model with growth shocks.

${ }^{7}$ Bengui and Bianchi (2014) study the case where taxes on debt are not perfectly enforceable and show that while this creates a trade-off between prudential benefits and allocative inefficiencies, taxes are still desirable.

${ }^{8}$ When $\mu_{t}>0$, there is a range of taxes that implements the constrained efficient allocations. In particular, $\tau$ such that $u^{\prime}\left(c_{t}\right)>\beta R(1+\tau) E u^{\prime}\left(c_{t+1}\right)$ with all variables evaluated at the allocations of the social planner implements the same allocations. Notice that a zero tax implements these allocations if and only if $u^{\prime}\left(c_{t}\right)>\beta R E u^{\prime}\left(c_{t+1}\right)$.
} 


\section{Quantitative Analysis}

\subsection{Calibration}

The parameterization follows closely the one proposed by Bianchi (2011), which was based on data for Argentina, but removing the shocks to the nontradables endowment. This was done to keep the set of exogenous shocks small in order to facilitate the numerical analysis. The parameter values used to calibrate the model are shown in Table 1.

Table 1: Baseline Model Parameters

\begin{tabular}{|cc|}
\hline Parameter & Values \\
\hline$y^{N}$ & 1 \\
$N_{y^{T}}$ & 3 \\
$E\left[y^{T}\right]$ & 1 \\
$\rho_{y^{T}}$ & 0.54 \\
$\sigma_{y^{T}}$ & 0.059 \\
$\beta$ & 0.91 \\
$\gamma$ & 2 \\
$\eta$ & 0.205 \\
$\kappa$ & 0.32 \\
$\omega$ & 0.32 \\
$\theta$ & $\frac{2}{3}$ \\
$R^{h}$ & 1.0145 \\
$R^{l}$ & 0.9672 \\
$F_{h h}$ & 0.9333 \\
$F_{l l}$ & 0.6 \\
\hline
\end{tabular}

The coefficient of relative risk aversion is set to a $\gamma=2$, which is a standard value. The value of $\eta$ is crucial, because it determines the elasticity of substitution in consumption of tradables and nontradables $(1 /(1+\eta))$, which in turn affects the response of the price of nontradables to changes in sectoral consumption allocations and hence the size of the pecuniary externality. As Bianchi (2011) reports, empirical estimates of the elasticity of substitution range between 0.40 and 0.83 , and we use the same conservative benchmark he adopted, such that the elasticity of substitution is set at the upper bound of this range. Hence $\eta=0.205$.

The joint Markov process of the tradables endowment and news signals is set as follows. First, we use $\rho_{y^{T}}=0.54$ and $\sigma_{y^{T}}=0.059$, as estimated by Bianchi (2011) using data for Argentina. Second, we use the Tauchen-Hussey quadrature algorithm to construct a Markov process with three realizations $(N=3)$ that approximates the estimated tradables income process. Third, to set the precision of the date t signals about $y_{t+1}^{T}$, recall that we are assuming that the signals also 
have three realizations. Hence, $\theta=\frac{1}{3}$ would imply that news are completely uninformative and $\theta=1$ would make news a perfect predictor of $y_{t+1}^{T}$ as of date $t$. In the calibration baseline, we set $\theta$ to the mid point between these two extremes, so $\theta=\frac{2}{3}$. For simplicity, we also assume that the signal realizations and the vector of realizations of $y^{T}$ are identical.

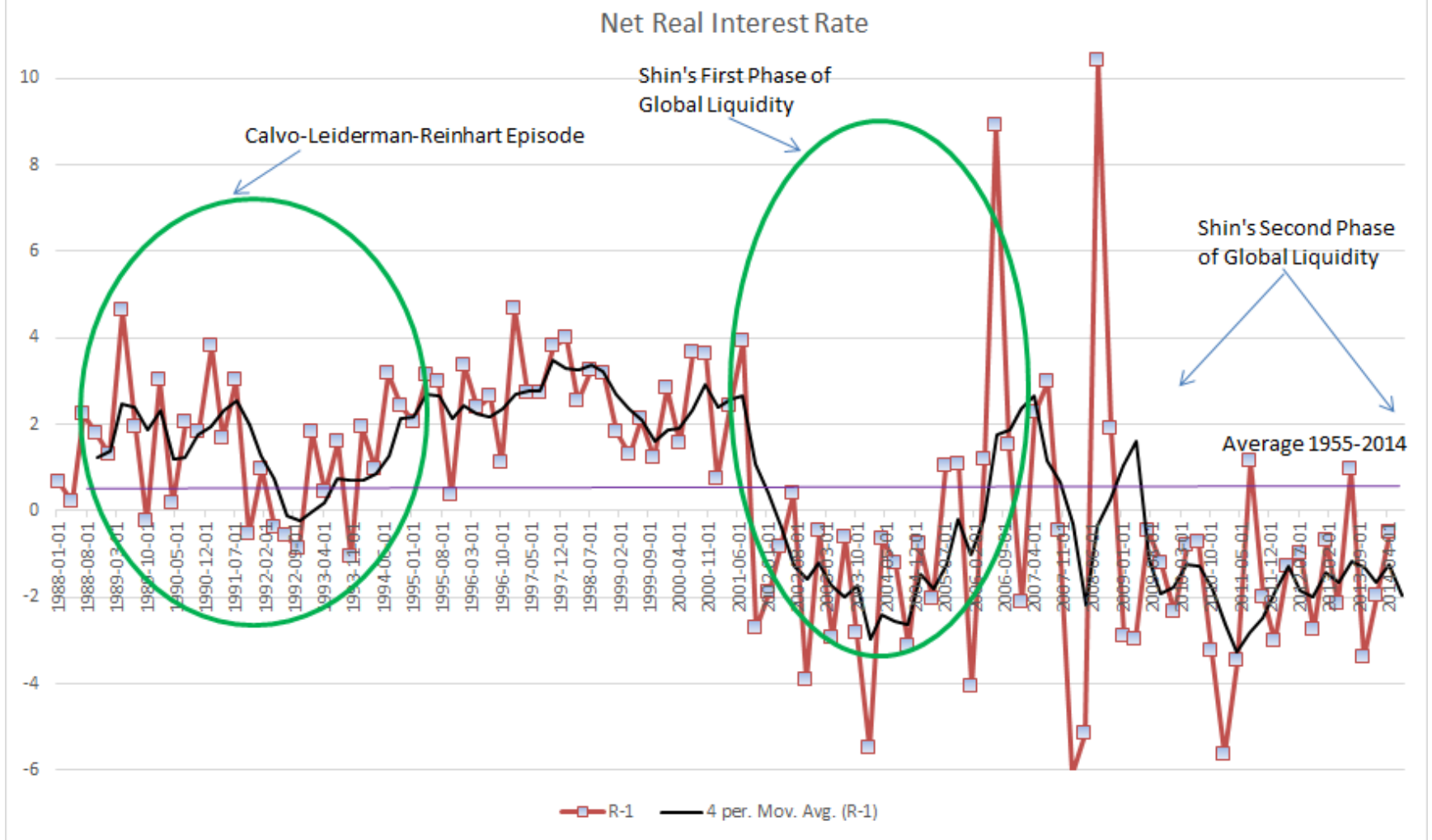

Figure 1: Global Liquidity Regimes

The regime-switching process of the world interest rate is calibrated to capture the global liquidity phases identified in the studies by Calvo et al. (1996) and Shin (2013), using data on the ex-post net real interest rate on 90-day U.S. treasury bills from the first quarter of 1955 to the third quarter of 2014 (see Figure 1). Calvo et al. (1996) identified in data for the 1988-1994 period a surge in capital inflows to emerging markets that coincided with a trough of -1 percent in the net U.S. real interest rate in the second half of 1993. Shin (2013) found two global liquidity phases, one in the first half of the 2000s with a real interest rate through of around -5.5 percent in early 2004, and another one in the aftermath of the 2008 global financial crisis, with the net real interest rate hovering around -3 percent since 2009. Taking the average over the troughs in the Calvo et al. sample and in the first of Shin's global liquidity phases, we set a -3.28 percent real interest rate for the high liquidity regime, which in gross terms implies $R^{l}=0.9672$. Given this, and the transition probabilities across regimes calibrated below, we set $R^{h}=1.0145$ so that the mean interest rate of the regime-switching process matches the full-sample average in our data, which was 0.76 percent. 
Constructing estimates of the duration of the global liquidity phases is more difficult, because the era of financial globalization, and hence global liquidity shifts, started in the 1980s, and of the three global liquidity phases observed since then, the third is heavily influenced by the unconventional policies used to contain the 2008 crisis. Using data from the first two phases, it follows that the duration of $R^{l}$ was 10 quarters, which thus leaves a duration of 60 quarters for $R^{h}$, starting the sample in 1980. Taking these as rough estimates of the mean durations of each regime yields $F_{h h}=0.9333$ and $F_{l l}=0.6$ at annual frequency, .

The discount factor $\beta$ is set to match an average net foreign asset position-GDP ratio of -0.29 , which is the average for Argentina in the data of Lane and Milesi-Ferretti (2001). We set $\omega=0.32$ to obtain a share of tradable output of 0.32 for Argentina in a deterministic version of the model with constant $b$. Given the calibrated value of $b, \omega$ is obtained from $\frac{y^{T}}{\frac{1-\omega}{\omega}\left(\frac{y^{T}+(R-1) b}{y^{N}}\right)^{\eta+1} y^{N}+y^{T}}=0.32$ 9. Finally, we set $\kappa=0.32$, as in Bianchi (2011), which delivers a a probability of financial crises of 3 percent, in the range of the empirical estimates.

The model is solved using a time-iteration method as in Bianchi (2011), but with the difference that we introduce the news about the tradables income and the regime-switching interest-rate shocks. Online appendix describes the solution method in detail and provides references to the Matlab code to solve the model.

\subsection{Long-run and Financial Crisis Moments}

Table 2 shows a set of the moments that characterize the decentralized equilibrium without policy intervention (DE) and the social planner's equilibrium (SP) with the optimal macroprudential policy. The top panel shows three key long-run moments, the mean net foreign asset positionGDP ratio, the standard deviation of the current account-output ratio, and the probability of a financial crisis, and also the welfare gain of adopting the optimal policy. ${ }^{10}$ The mean debt ratios just under 30 percent are about the same in the two scenarios (recall the DE baseline calibration set $\beta=0.91$ to mach the average NFA-GDP ratio in the data for Argentina, which is 29 percent), but the variability of the current account in DE is roughly twice as large as in SP. Thus, the two economies support the same long-run debt position, but the optimal macroprudential policy reduces the volatility of capital flows by a half. The policy also reduces the probability of crisis from 3.5 percent in DE to 2.3 percent in SP. These findings are in line with Bianchi (2011) who

\footnotetext{
${ }^{9}$ The mean value for the tradables endowment and the endowment of non-tradables are set to one. This is an innocuous assumption. Since we calibrate the model to match the observed share of tradables output in total output, 0.32 , a different value for $y^{N}$ would lead to a different calibrated value of the preference parameter $\omega$, which in turn, would keep the total income unchanged. Thus a different value of $y^{N}$ would not change the borrowing decisions

${ }^{10}$ See the notes to Table 2 for the definitions of crisis and welfare used in these exercises.
} 
showed that optimal macroprudential policy achieves significant reduction in volatility despite low effects on average debt levels.

Table 2: Baseline Model Moments

\begin{tabular}{lll}
\hline & $(1)$ & $(2)$ \\
Long-run Moments & $\mathrm{DE}$ & $\mathrm{SP}$ \\
\hline$E[B / Y] \%$ & -29.62 & -29.31 \\
$\sigma(C A / Y) \%$ & 3.18 & 1.75 \\
Welfare Gain $1 \%$ & $\mathrm{n} / \mathrm{a}$ & 0.12 \\
Prob of Crisis ${ }^{2} \%$ & 3.51 & 2.27 \\
\hline \multicolumn{3}{c}{ Financial Crisis Moments } \\
\hline$\Delta C \%$ & -14.39 & -9.41 \\
$\Delta R E R \%$ & -45.55 & -27.62 \\
$\Delta C A / Y \%$ & 13.47 & 7.06 \\
$\Omega^{C} 3$ & 4.63 & 3.25 \\
$\Omega^{R E R}$ & 5.61 & 3.69 \\
$\Omega^{C A / Y} \%$ & 13.37 & 7.38 \\
$E[\tau]$ pre-crisis ${ }^{4} \%$ & n/a & 4.65 \\
\hline \multicolumn{2}{c}{ Switch from $R_{l}$ to $R_{h}$} & \\
\hline$\Delta C \%$ & -15.49 & -10.18 \\
$\Delta R E R \%$ & -49.93 & -30.25 \\
$\Delta C A / Y \%$ pre-crisis $\%$ & 14.65 & 7.70 \\
\hline
\end{tabular}

${ }^{1}$ Welfare gains are computed as compensating variations in consumption constant across dates and states that equate welfare in the DE and SP. The welfare gain $W$ at state $(\mathrm{b}, \mathrm{z})$ is given by $(1+W(b, z))^{1-\sigma} V^{D E}(b, z)=$ $V^{S P}(b, z)$. The long-run average is computed using the ergodic distribution of the DE.

${ }^{2} \mathrm{~A}$ financial crisis is defined as a period in which the constraint binds and the current account $(\mathrm{CA} / \mathrm{Y})$ raises by more than two standard deviations in the ergodic distribution of the decentralized economy, i.e. when $(\mathrm{CA} / \mathrm{Y})$ is larger than 6.4 percent.

${ }^{3}$ The values of $\Omega$ are financial amplification coefficients, which are ratios of the average impact effects displayed by each variable in financial crises states over the average impact effects that shocks of the same magnitude produce in non-crises states.

${ }^{4}$ Average $\tau$ in the periods before financial crises.

The mid panel of Table 2 shows moments that summarize the main features of financial crises in both the DE and SP solutions. First we report three statistics about the average magnitude of crises: the drops in aggregate consumption $(\Delta C)$ and the real exchange rate $(\Delta R E R)$ and the reversal in the current account-output ratio $(\Delta C A / Y)$. These statistics are averages of the impact effects that occur when a financial crisis hits, computed using each economy's long-run distribution of the state variables $(b, z)$ conditional on the economy being in a financial crisis state. The Table also shows the average macroprudential tax before a crisis occurs $(E[\tau]$ pre-crisis $)$, and a set of financial amplification coefficients $\left(\Omega^{i}\right.$ for $\left.i=C, R E R, C A / y\right)$. These coefficients measure 
the excess response of each variable in states with $b$ such that a financial crisis occurs relative to states with $b$ such that the financial crisis does not occur, both with identical values of $z$.

The results in the DE column show that financial crises in this model result in large declines in consumption and the real exchange rate, and large current-account reversals. Moreover, financial amplification is strong, because the large $\Omega$ coefficient imply that the same shocks generate significantly larger responses in financial crises states than in non-crises states. This finding is in line with the results reported in Mendoza (2010), showing large amplification coefficients in a model in which the Fisherian mechanism is introduced via a credit constraint using physical capital as collateral in an otherwise conventional RBC model of the small open economy.

Comparing across DE and SP columns shows that an average pre-crisis tax of 4.6 percent reduces significantly both the magnitude of the average crisis and financial amplification on consumption, relative prices and capital inflows. Hence, the optimal policy is quite effective at reducing the probability and the magnitude of financial crises.

The bottom panel of Table 2 isolates the effects of switches from high global liquidity $\left(R^{l}\right)$ to low global liquidity $\left(R^{h}\right)$. The probability of these particular kind of crisis is low, because by construction of the regime-switching Markov chain these switches are infrequent. When this crises occur, however, financial crises are more severe, resulting in impact effects on consumption, the real exchange rate and the current account larger than on the average financial crisis. As a result, the average optimal tax pre-crisis is also higher than in the average crisis (5.1 v. 4.7 percent).

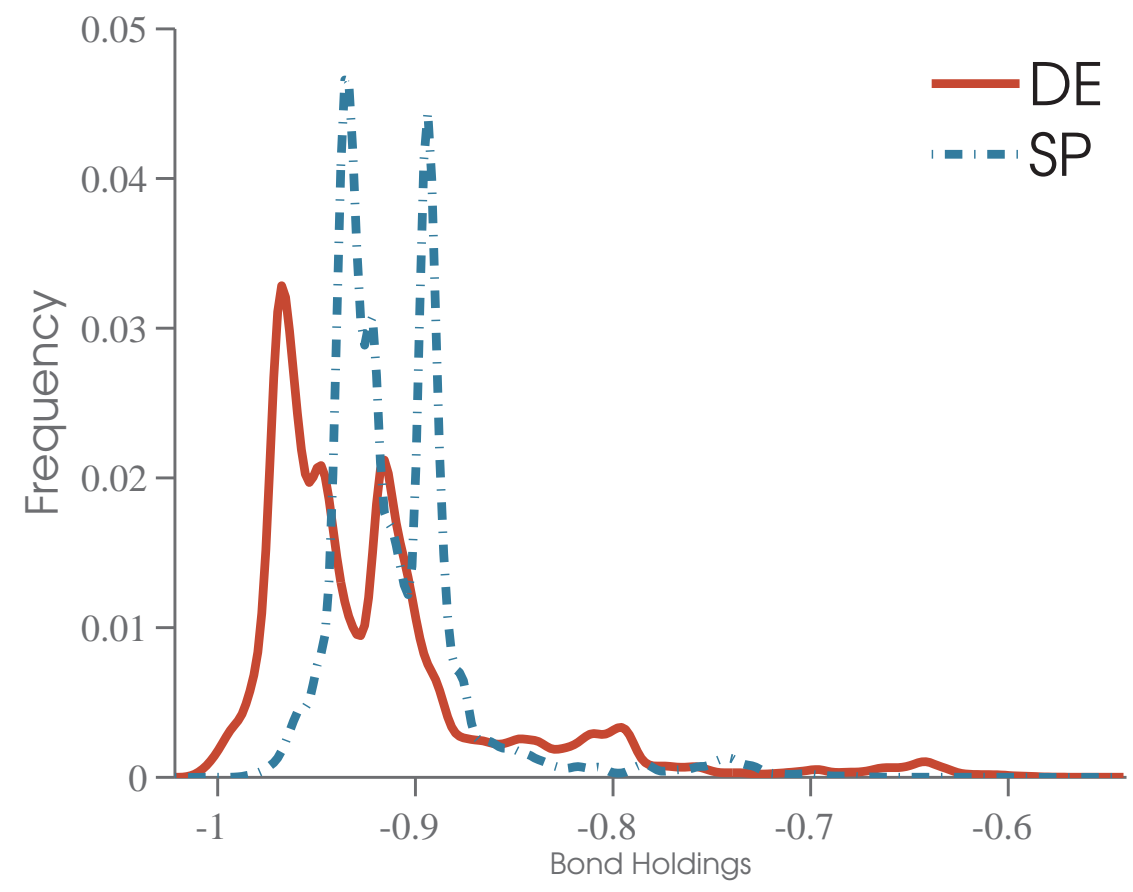

Figure 2: Ergodic Distributions of Bond Holdings

The effects of the pecuniary externality on borrowing choices, particularly the incentive to overborrow in the DE, and the effectiveness of the macroprudential policy at containing these 
effects are both illustrated in the long-run distribution of bond holdings shown in Figure 2. The planner's distribution is clearly shifted to the right of the distribution in the DE. Note also that the twin-peaked nature of these distributions results from the twin-peaked distribution of interest-rate shocks characteristic of the regime-switching specification.

\subsection{Crisis Dynamics}

We study next macro dynamics around crisis events. Figure 3 plots event-analysis windows that highlight these dynamics. The windows span seven years centered on the year a crisis occurs. ${ }^{11}$ The movements observed when financial crises hit emerge clearly as sharp, non-linear fluctuations relative to the smooth pre- and post-crises patterns. The plots also compare the dynamics of the DE with those of the SP. The effectiveness of the optimal macroprudential policy at reducing the severity of crises is evident in these event windows.

(a). RER

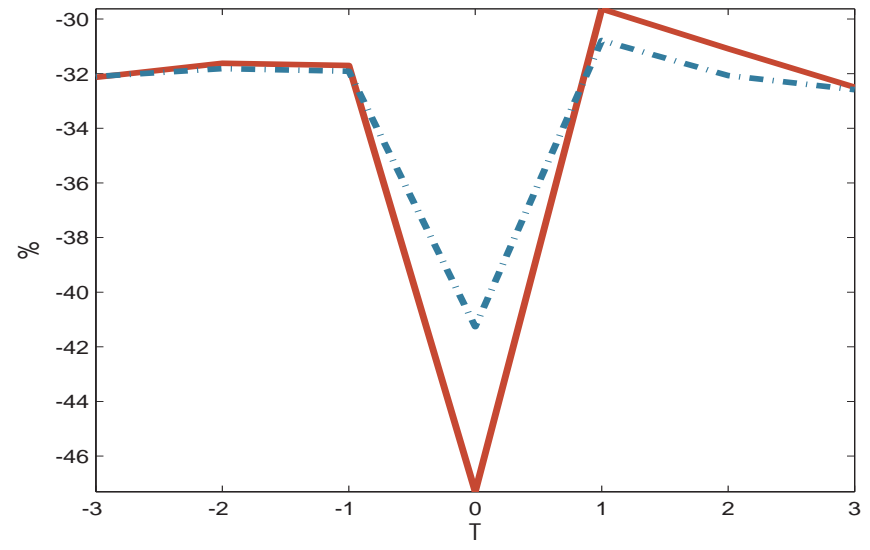

(C). $c^{\top}$

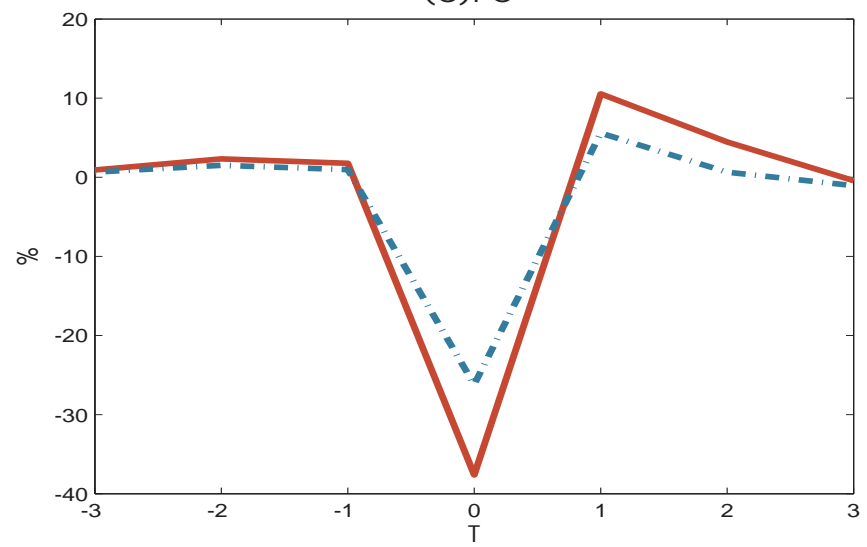

(b). B

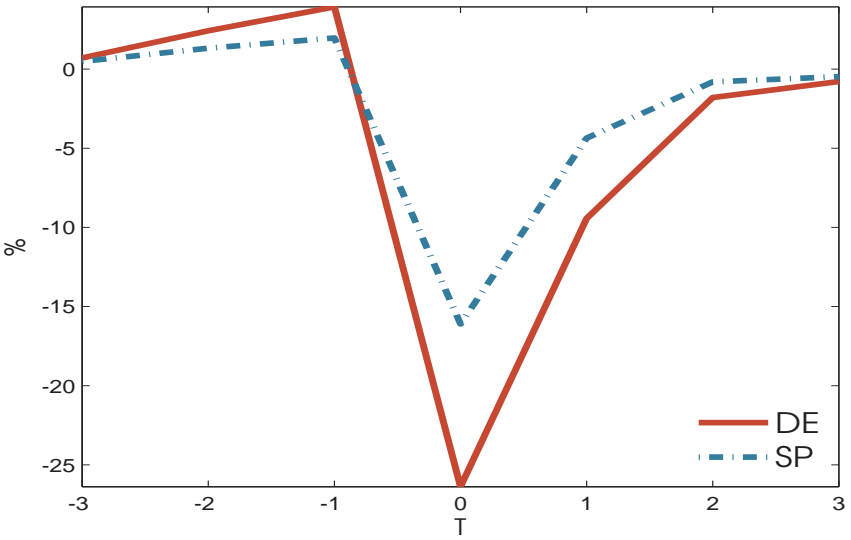

(d). CA/Y

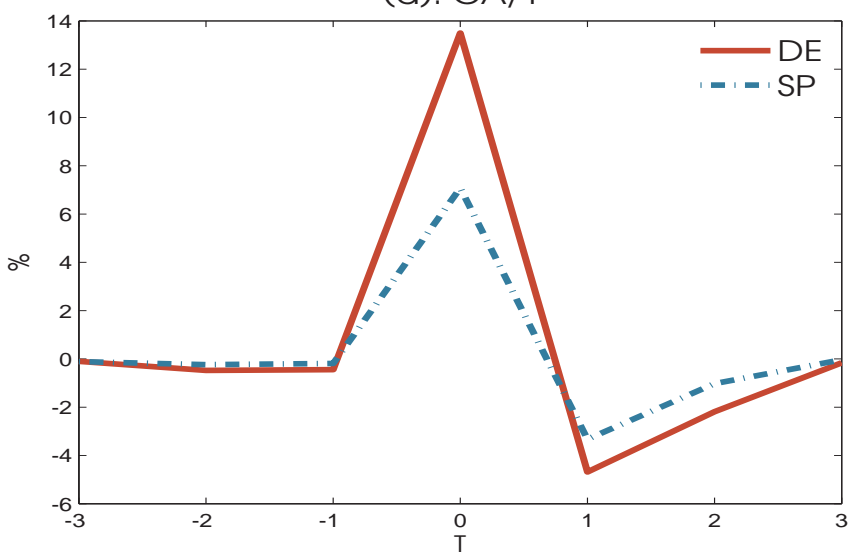

Figure 3: Baseline DE vs SP around Crisis (Deviation from Mean)

Figure 4 illustrates the composition of the mix of shocks at work in the model in the seven

\footnotetext{
${ }^{11}$ Details of the event-analysis construction are documented in the online appendix.
} 
periods covered in the event windows, by plotting the fraction of realizations of each shock that were observed each year. Panel (a) is for news signals, (b) for interest rate regimes, and (c) for tradables income shocks. As one would expect, financial crises are periods that largely coincide with high real interest rates and low income realizations. But what is more interesting, and captures the effects of the news shocks discussed in the previous Section, is that financial crises only occur about half the time when bad news are received (i.e. at $t=0$ in the top panel of Figure 4, good or average news occur with about 0.5 frequency). Moreover, in the pre-crisis phase the interest rate is more likely to be high and the income realization more likely to be average, but good news are likely to be received with about 40 percent frequency in the period before a financial crisis hits. Hence, financial crises in which news are good a year before but the actual income realization turns out to be low are typical. ${ }^{12}$

(a). News Signals
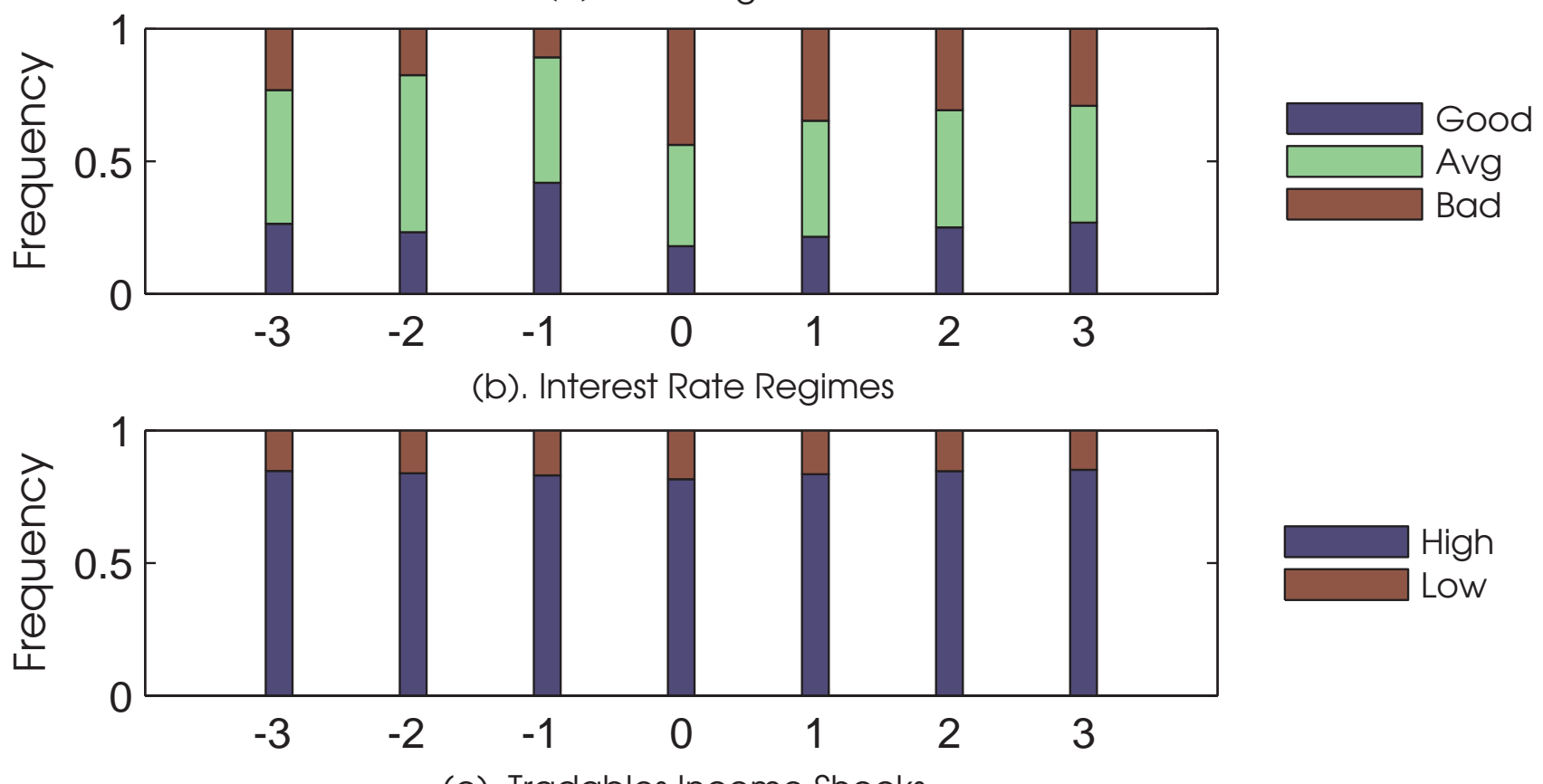

(c). Tradables Income Shocks

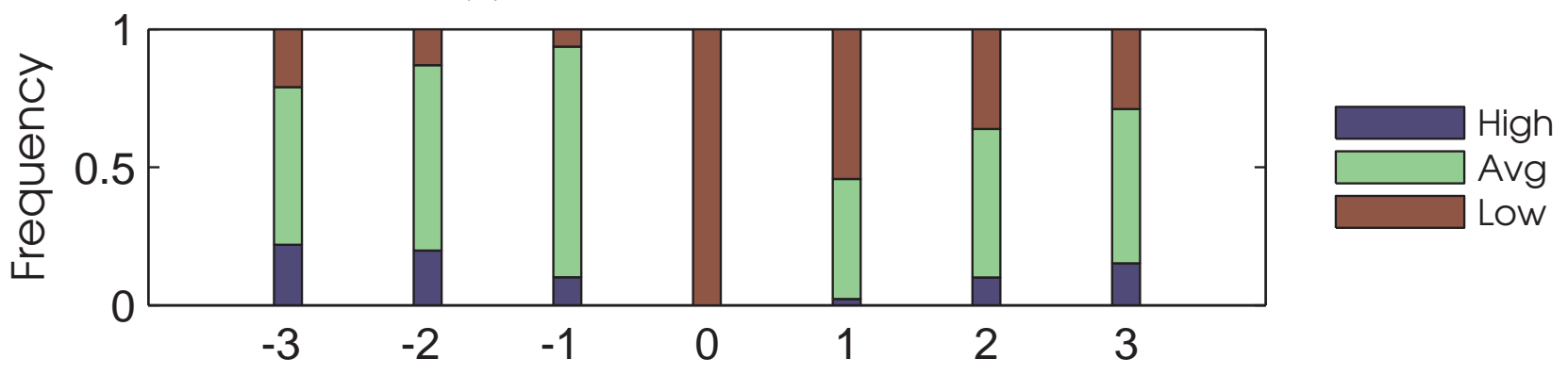

Figure 4: Baseline Exogenous States around Crisis

Figures 5 and 6 illustrate further the role of news and regime changes in the interest rate in

\footnotetext{
${ }^{12}$ Akinci and Chahrour (2014) also studies how noisy news contribute to magnify credit booms.
} 
driving financial crises. Figure 5 shows a breakdown of the three indicators of the magnitude of a crisis at date $t$ (the drops in consumption and the real exchange rate, and the current account reversal) and the debt tax at $t-1$ across realizations of good, average and bad news at $t-1$. This Figure shows that, for all three indicators, crises preceded by good or average news are significantly worse than those preceded by bad news. Interestingly, the optimal tax in the year before a crisis is much higher with either good or bad news than with average news.

(a). $c^{\top}$ in Crises

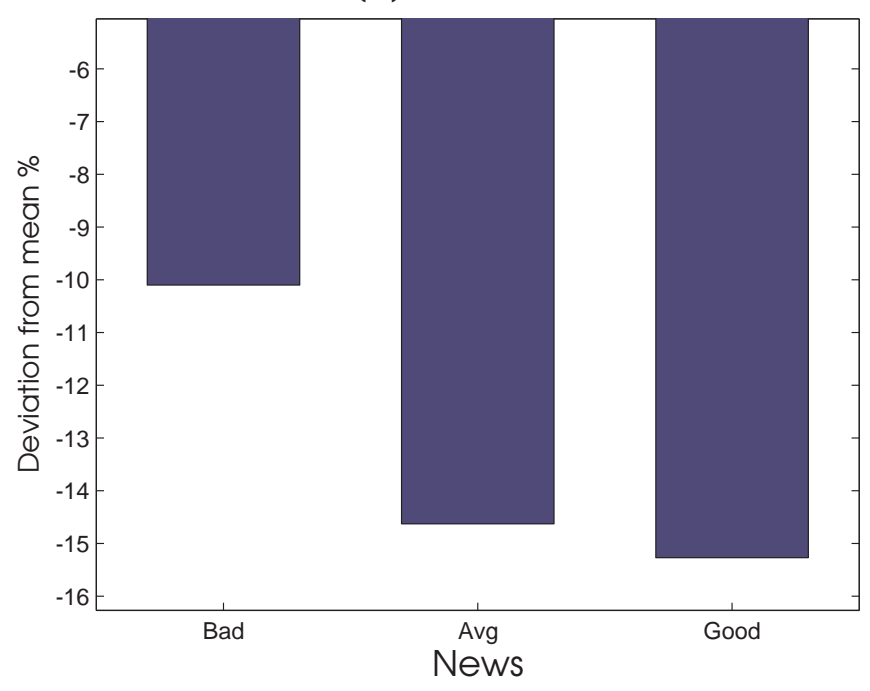

(c). CA in Crises

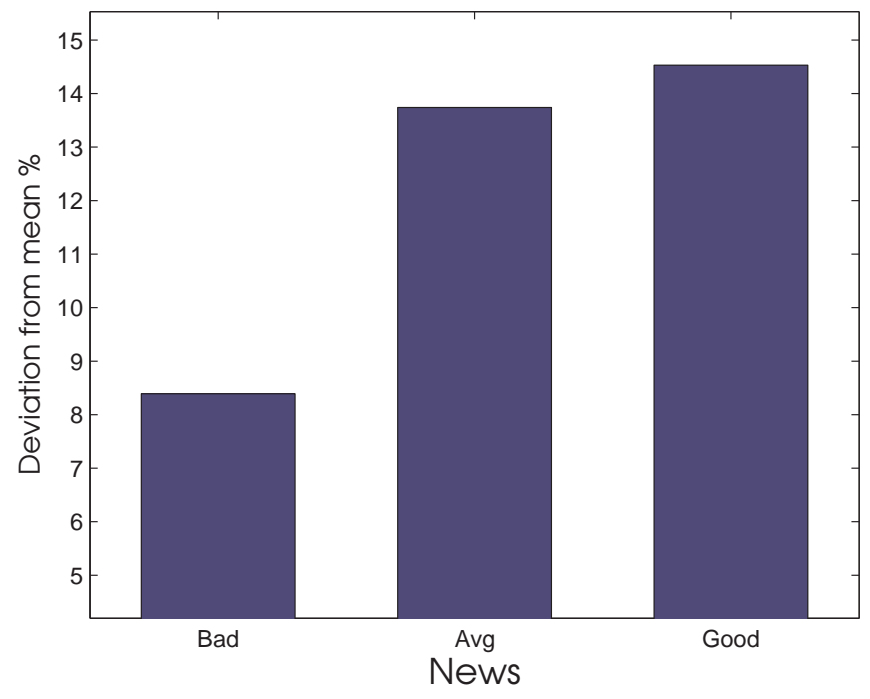

(b). RER in Crises

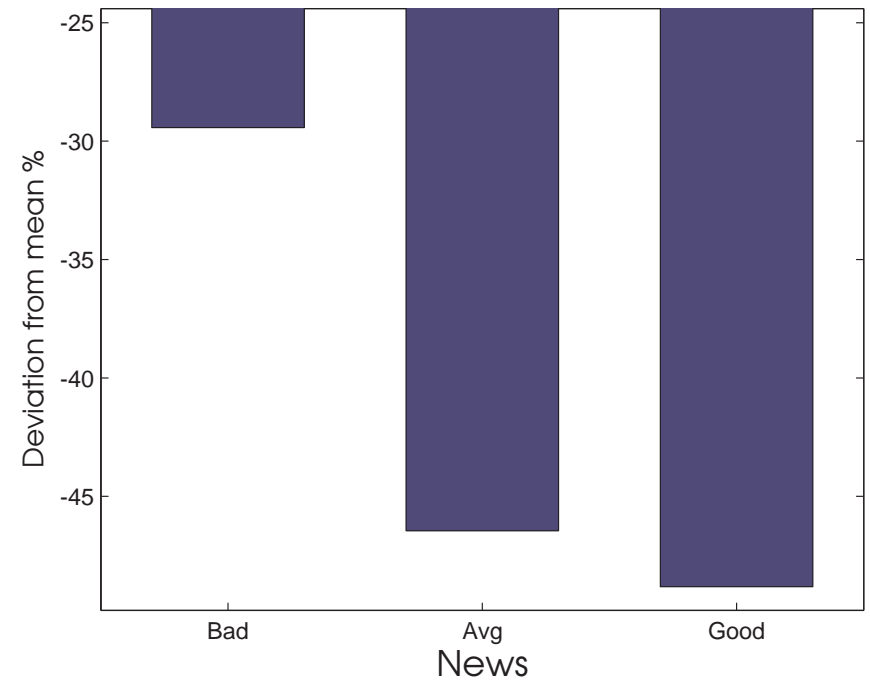

(d). Debt Tax before Crises

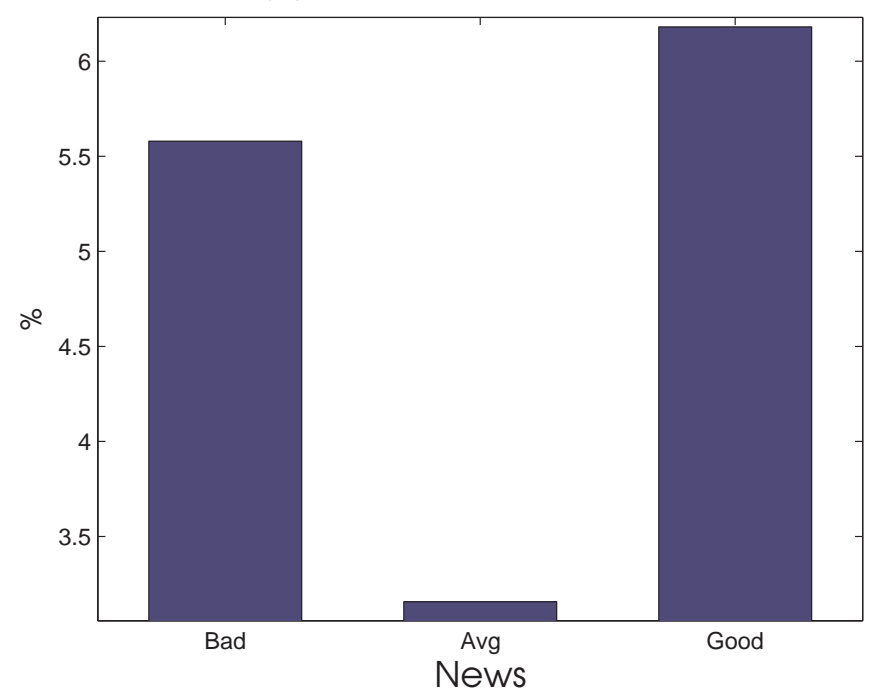

Figure 5: Breakdown of Crises Effects and Optimal Tax across News Signals at t-1

Figure 6 shows a similar breakdown for the crisis indicators and the optimal tax before a crisis, but now in terms of crises characterized by either $R^{l}$ at t- 1 and $\mathrm{t}-2$ and a switch to $R^{h}$ at date $\mathrm{t}$ (labeled the "High Liquidity" case) or $R^{h}$ in all three periods (labeled the "Low Liquidity" case). Thus, in the former case the crisis is preceded by the high liquidity regime and coincides with a switch of regime, while in the latter the low liquidity regime was present before and during the 
crisis. ${ }^{13}$ Crises with a change to the low liquidity regime and preceded by high liquidity are larger than those that occur without a switch, and the optimal policy displays debt taxes that are about 50 basis points larger.

(a). $c^{\top}$ in Crises

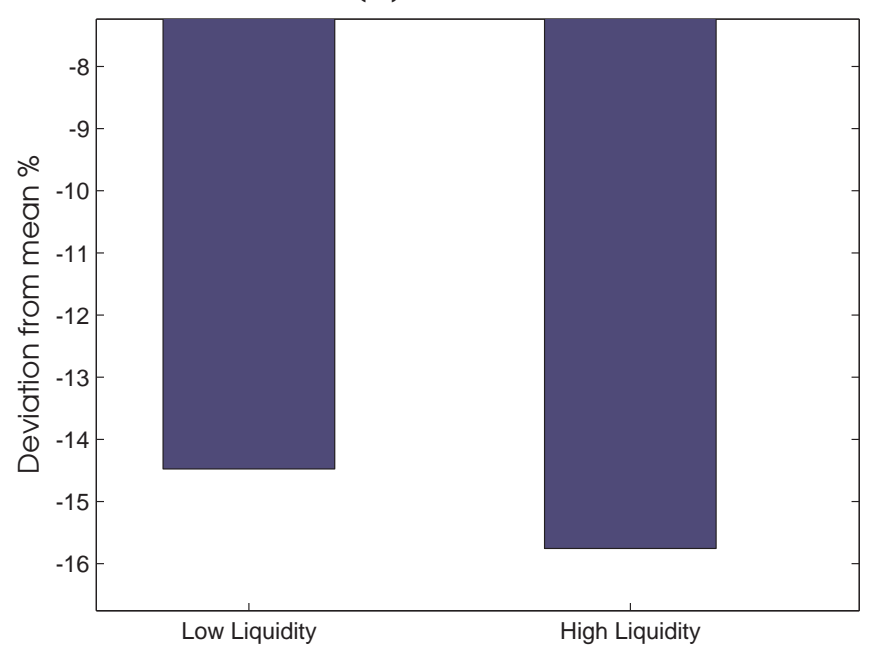

(c). CA in Crises

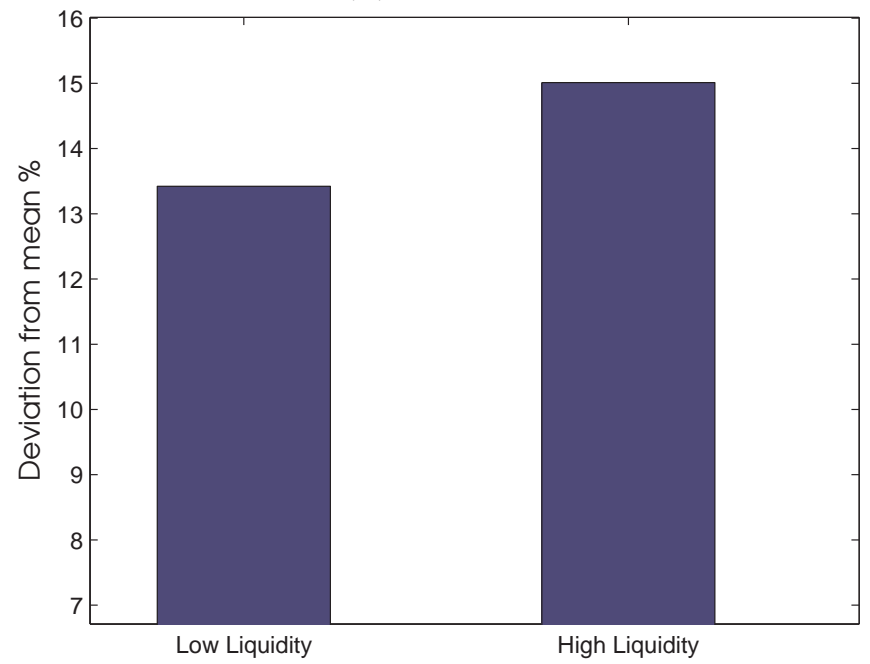

(b). RER in Crises

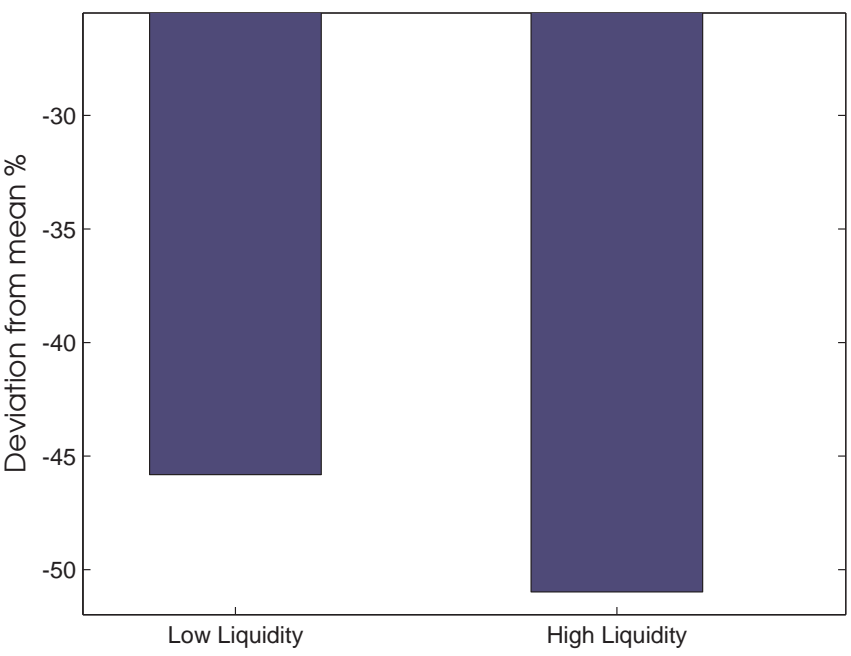

(d). Debt Tax before Crises

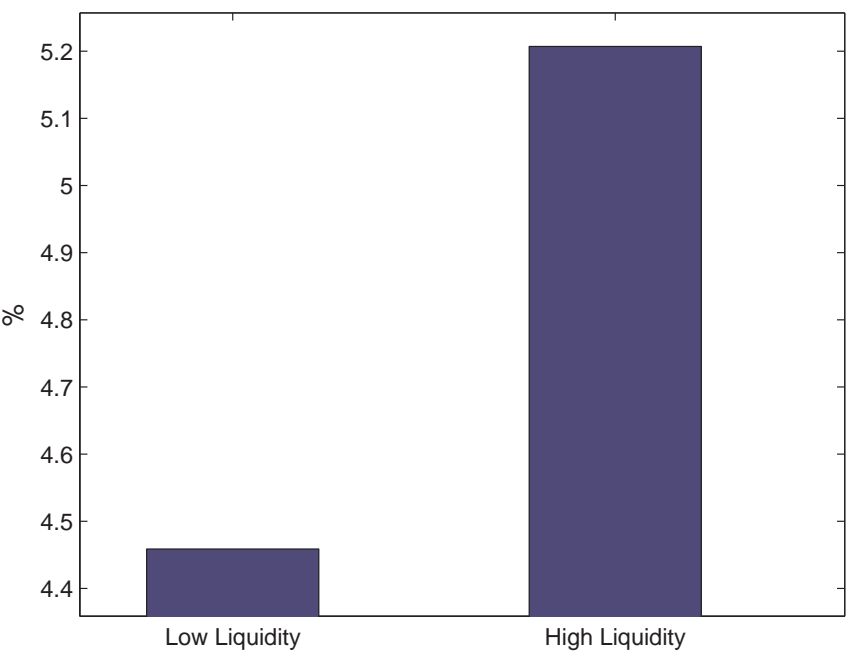

Figure 6: Breakdown of Crises Effects and Optimal Tax across Liquidity Regimes

Figure 7 shows the evolution of the optimal macroprudential tax in the seven-year crisis windows, and also compares the tax dynamics for the baseline value of $\theta$ with two alternatives, one where news are less informative (low $\theta$ ) and one in which news are very informative (high $\theta$ ). We discuss the effects of news precision later in this Section. In the baseline case, the plot shows the pro-cyclical nature of the optimal tax. The tax rises from about 3.5 to nearly 5 percent in the years before the crisis, and then drops at the time of the crisis. The tax rises rapidly again in the years after the crisis, which indicates that the policy is quite active most periods and entails

\footnotetext{
${ }^{13}$ Due to the regime-switching specification of the interest rates process, there are significantly fewer crisis with $R^{h}$ at that had $R^{l}$ since t-3 than since t-2, and hence we used the latter to represent the high global liquidity scenario.
} 
significant variability across states of nature.

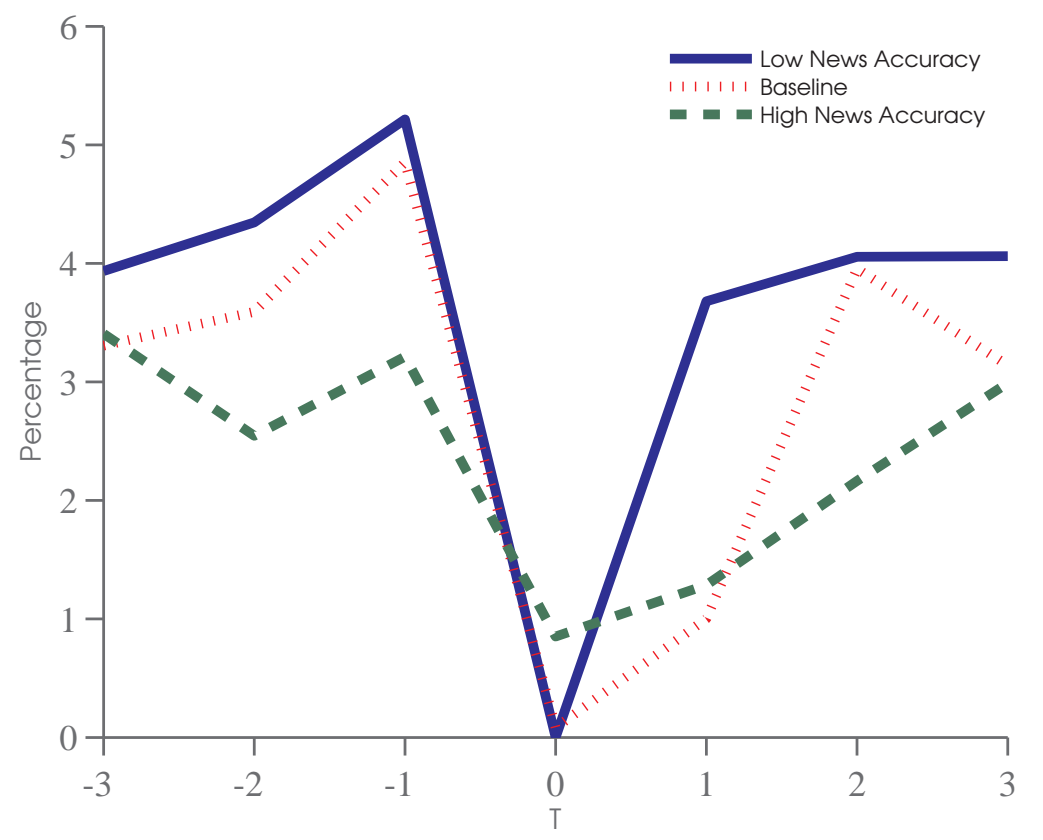

Figure 7: Optimal Debt Tax around Crises

\subsection{Complexity of the Optimal Policy}

We illustrate the complexity of the optimal macroprudential policy that implements the SP's allocations by studying how the optimal tax varies across states of nature, particularly across news signals and liquidity regimes. We examine first how the tax varies with the three values that the news signal can take. Figure 8 shows the schedule of debt taxes for bad, average and good news as a function of the value of $b$ organized in four plots: (a) for low $y^{T}$ and $R_{h}$, (b) for high $y^{T}$ and $R_{h}$, (c) for low $y^{T}$ and $R_{l}$, and (d) for high $y^{T}$ and $R_{l}$. When the date-t income shock is high, debt taxes tend to be the highest when bad news about income at $t+1$ arrive, and they fall as the news turn average or good (for both $R_{h}$ and $R_{l}$ ). But the ranking changes when the income shock is low, and in this case the ordering also varies depending on whether $b$ is relatively low or high. In particular, for sufficiently low $b$ the ordering of debt taxes as news vary is the

opposite of what we obtained when $y^{T}$ is high: Debt taxes are the highest when news is good, and fall as news turns average to bad. This pattern once again reflects the opposing forces affecting borrowing decisions in the presence of noisy news, and their interaction with the actual income realization. What does remain the case in all scenarios is that, for sufficiently high $b$ the tax is zero (this is the region where the credit constraint does not bind at $t$ and is not expected to bind at $t+1$ ), and that as $b$ falls below a threshold value the debt tax always rises as $b$ falls (i.e. the debt tax is increasing in debt). 
Figure 9 shows a similar analysis of the debt tax as Figure 8 but now highlighting how debt taxes differ across global liquidity regimes. In this case, we find that debt taxes, when present, are always higher in states with high global liquidity $\left(R_{l}\right)$ than with low global liquidity $\left(R_{h}\right)$, and can reach slightly above 10 percent for low $y^{T}$, good news with either high or low world interest rates. Moreover, there is always a range of debt positions for which the tax is zero and invariant if global liquidity is low, but positive and increasing as debt rises if global liquidity is high. Thus, these results show that optimal macroprudential policy also needs to incorporate variation in the policy instrument in response to changes in world financial conditions.

(a). Low $\mathrm{y}^{\top}$,High $\mathrm{R}$

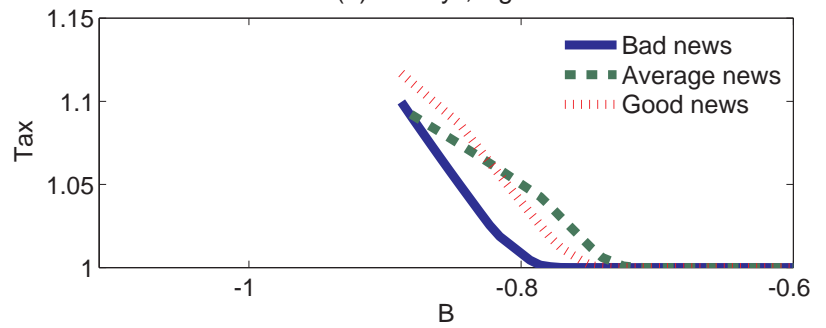

(c). Low $\mathrm{y}^{\top}$, Low $\mathrm{R}$

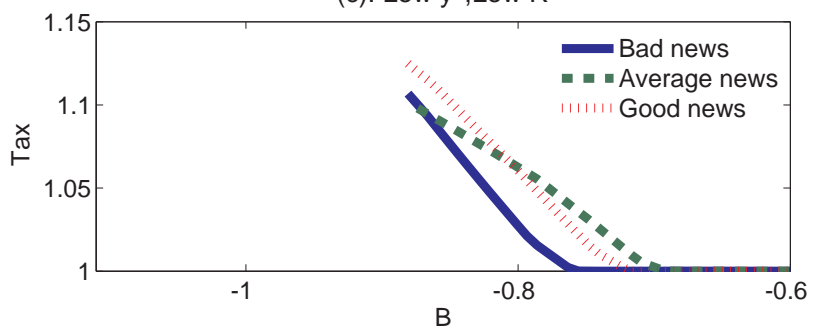

(b). High $\mathrm{y}^{\top}$, High R

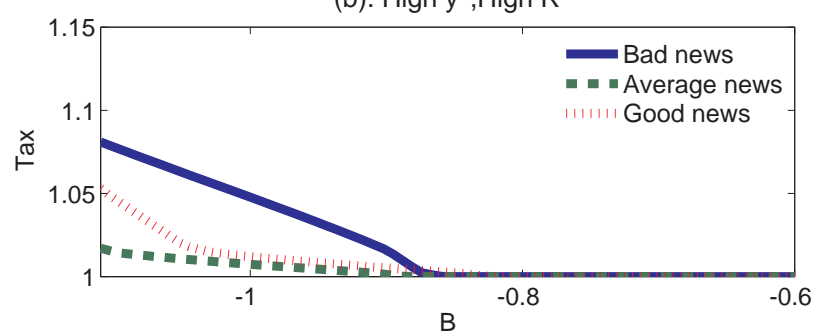

(d). High $\mathrm{y}^{\top}$,Low $\mathrm{R}$

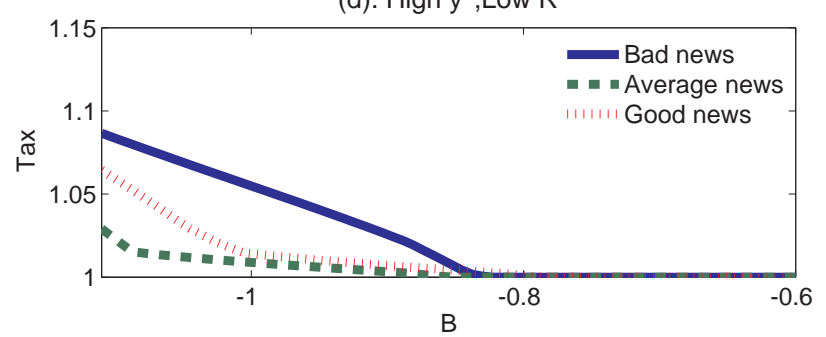

Figure 8: Baseline Debt Tax: Effect of News

(a). Bad news, Low $\mathrm{y}^{\top}$

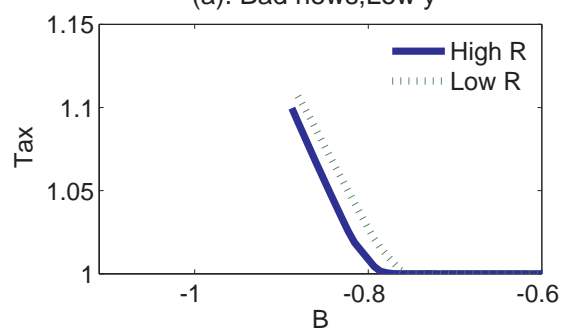

(d). Bad news, High $\mathrm{y}^{\top}$

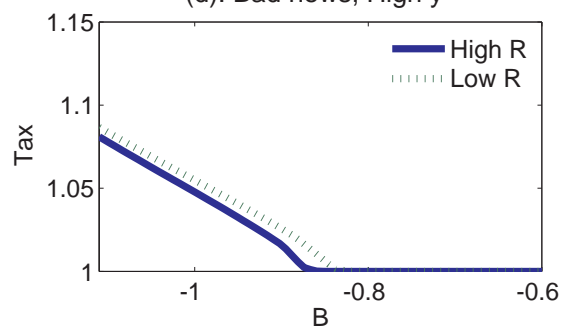

(b). Avg news, Low $\mathrm{y}^{\top}$

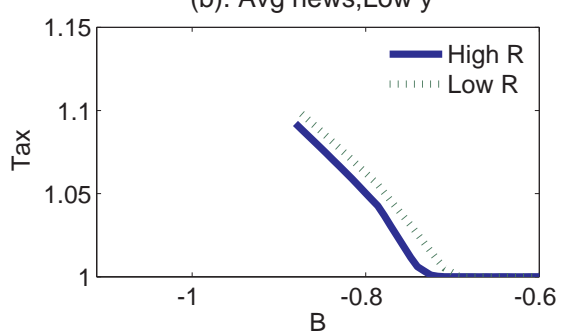

(e). Avg news, High $\mathrm{y}^{\top}$

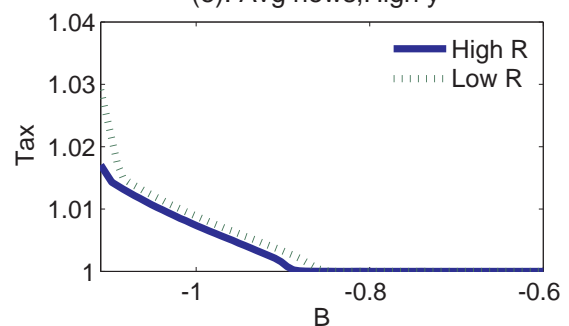

(c). Good news, Low $\mathrm{y}^{\mathrm{T}}$

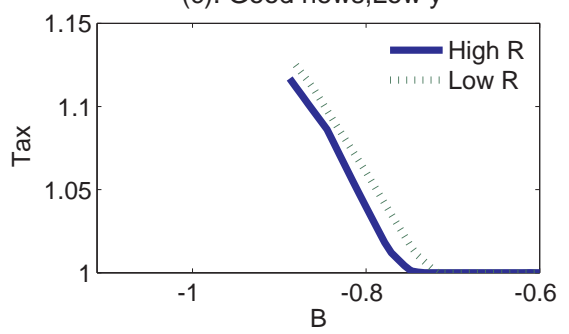

(f). Good news, High $\mathrm{y}^{\top}$

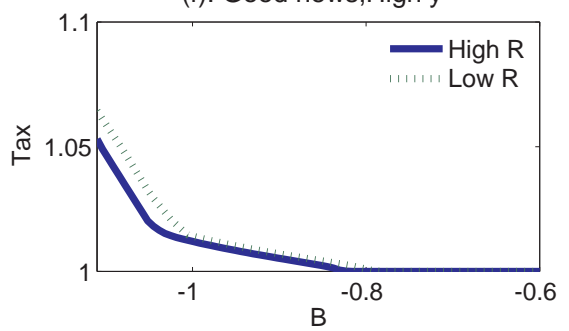

Figure 9: Baseline Debt Tax: Effect of Interest Rate Shifts 


\subsection{Effects of News Precision}

We examine next how the precision of news affects the magnitude and frequency of financial crises, the average optimal tax, and the welfare gains of the optimal policy. This analysis aims to show two main points: First, that as news become more accurate, the economy in the decentralized equilibrium experiences less frequent but more severe crises. Second, that the effectiveness of the optimal policy, in terms of how much it reduces the frequency and magnitude of crises and how large a welfare gain it yields, falls as the precision of the news improves.

Figure 10 reports how the moments reported for the baseline scenario in Table 2 change as the precision of the date-t news about $y_{t+1}^{T}$ varies. The baseline precision was set to $\theta=0.67$, and Figure 10 compares this scenario with four alternatives, two with lower precision $(\theta=0.35,0.55)$ and two with higher precision $(\theta=0.77,0.87) .{ }^{14}$ Recall that news are completely uninformative for $\theta=0.33$, and that for $\theta=1$ the news predict perfectly the value of $y_{t+1}^{T}$ as of date t. Hence, the values considered in Figure 10 range from nearly completely uninformative news to nearly perfectly informative news. Figure 10 shows the effects of the same variations in the precision of news on the mean net foreign asset position, the standard deviation of the current account, the probability of crisis, the welfare gain of the optimal policy, and the crisis effects on the current account, consumption and real exchange rate.

Figure 10 shows that the mean of $b / y$ falls for both DE and SP as the signal precision improves. This is because as signals become more informative they reduce the uncertainty about tomorrow's income, and thus the incentive for self insurance weakens. Because of the increase in debt, more informative news may lead to higher current account variability. In fact, the variability of the current account rises monotonically with the precision of the news in SP (and is non-monotonic for $\mathrm{DE}$ ). The effect is small because this reduction in uncertainty affects the income realization at $t+1$ expected as of date $t$, and hence has a much smaller effect on the overall income uncertainty. The probability of financial crises in the DE declines monotonically from about 8 percent with $\theta=0.35$ to just below 2 percent with $\theta=0.87$, but for the SP the changes are non-monotonic. The probability first rises with $\theta$ and then falls when $\theta$ rises from 0.75 to 0.87 . These differences across DE and SP, and the non-monotonicity in the SP case, reflect the net result of the offsetting effects of news on borrowing decisions discussed earlier: Good news at date $t$ about $y_{t+1}^{T}$ induce additional borrowing at $t$, increasing financial vulnerability, while at the same time the expected future borrowing capacity rises, and reduces future borrowing. In the DE the second effect always dominates, but in the SP the first effect dominates at first as $\theta$ rises, but at high $\theta$ the second effect dominates. The difference across the DE and SP results is because of the interaction of the effects of news with the removal of the overborrowing effect of the pecuniary externality in the SP allocations.

\footnotetext{
${ }^{14}$ This monotonicity remains for values of $\theta$ closer to one for the maximum crisis for each simulation, but differences in crisis thresholds generate a less clear pattern for average crisis.
} 
Interestingly, the welfare gain of the policy is decreasing and concave in $\theta$. As $\theta$ rises from 0.33 to 0.67 the gain declines almost linearly from 0.13 to 0.11 , but after that it declines sharply to nearly 0.06 when $\theta$ reaches 0.87 .

The mid panel of Figure 10 show an important result: Higher news precision produces significantly larger financial crises in both the DE and SP. In the DE, the average consumption drop, real depreciation and current account reversal in a financial crisis are significantly larger with $\theta=0.87$ than with $\theta=0.35$ ( $-18.1 \mathrm{v}$. -10.2 percent for consumption, -64 percent v. -31 percent for the real exchange rate, and 19 v. 8.4 percentage points for the reversal in the current account-output ratio).
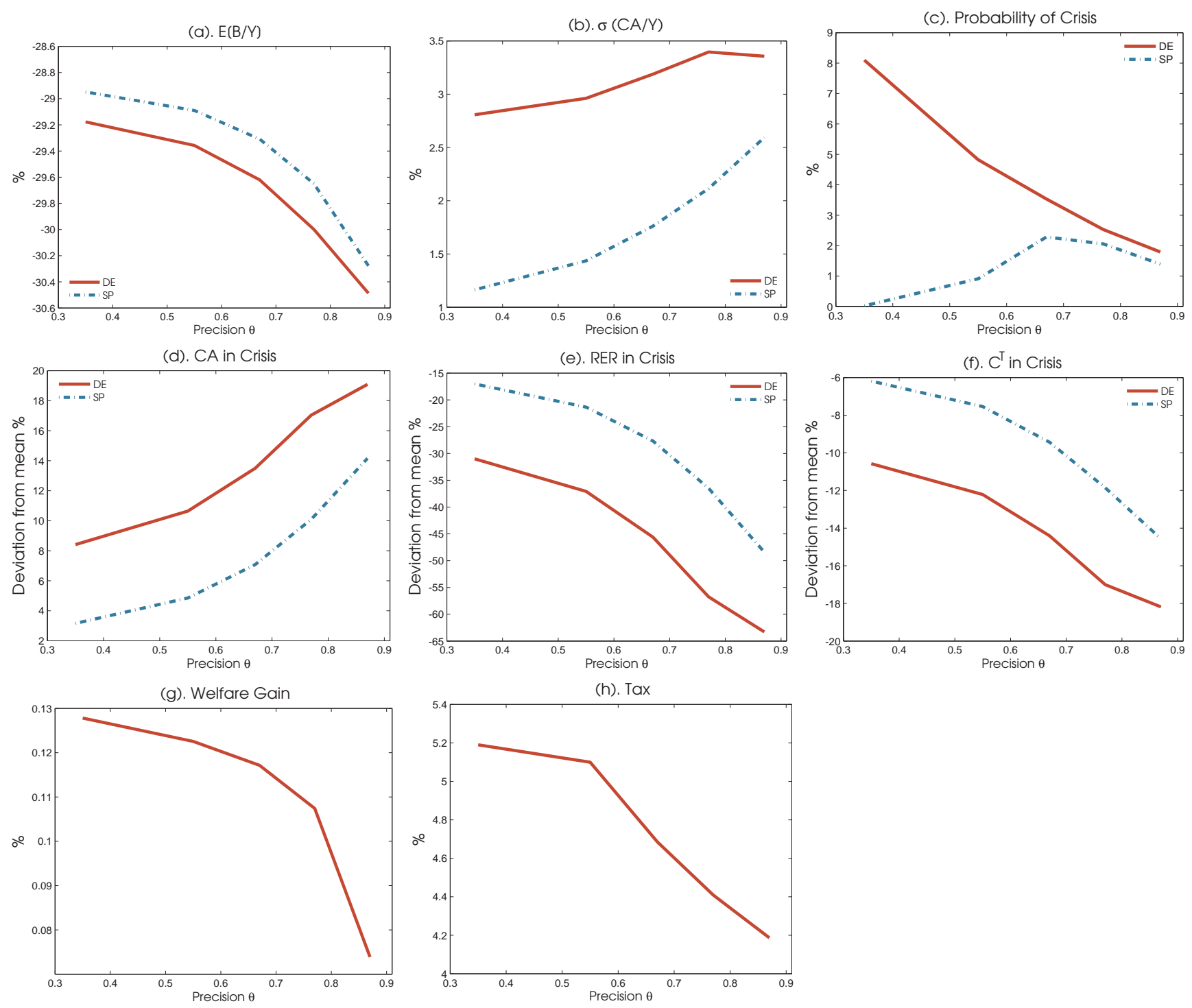

Figure 10: News Precision and Financial Crises Characteristics

Figure 11 shows the exogenous states preceding and in crises given different news precisions. We plot three-year crisis window: two periods before the crisis and the crisis period. The first row plots the frequency of bad news received for uninformative, average, and accurate news signal 
respectively. The second row plots the portion of high $\mathrm{R}$ regime and the third row shows frequency of low $y^{T}$ shock. The top panel shows graphically that crises follow good news holds for various news signal precisions. When news signals are uninformative, the frequency of bad news received is about one third across $t-2, t-1$ and $t$. But there are less and less bad news preceding crises as news precision increases. The $y^{T}$ shocks play an important role in triggering crisis when news are uninformative. The bottom panel shows that all crises coincide with low $y^{T}$ without any low $y^{T}$ preceding the crisis. Unlike the uninformative and average news signals, not all crises coincide with low $y^{T}$ shock for accurate news signal, indicating other forces other than $y^{T}$ shocks become important.

(a). Bad News around Crisis

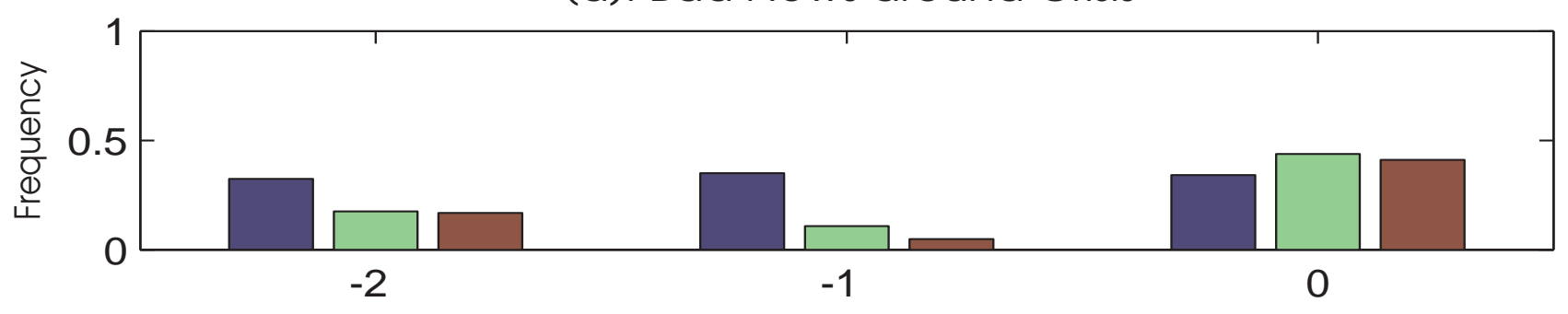

(a) High R around Crisis
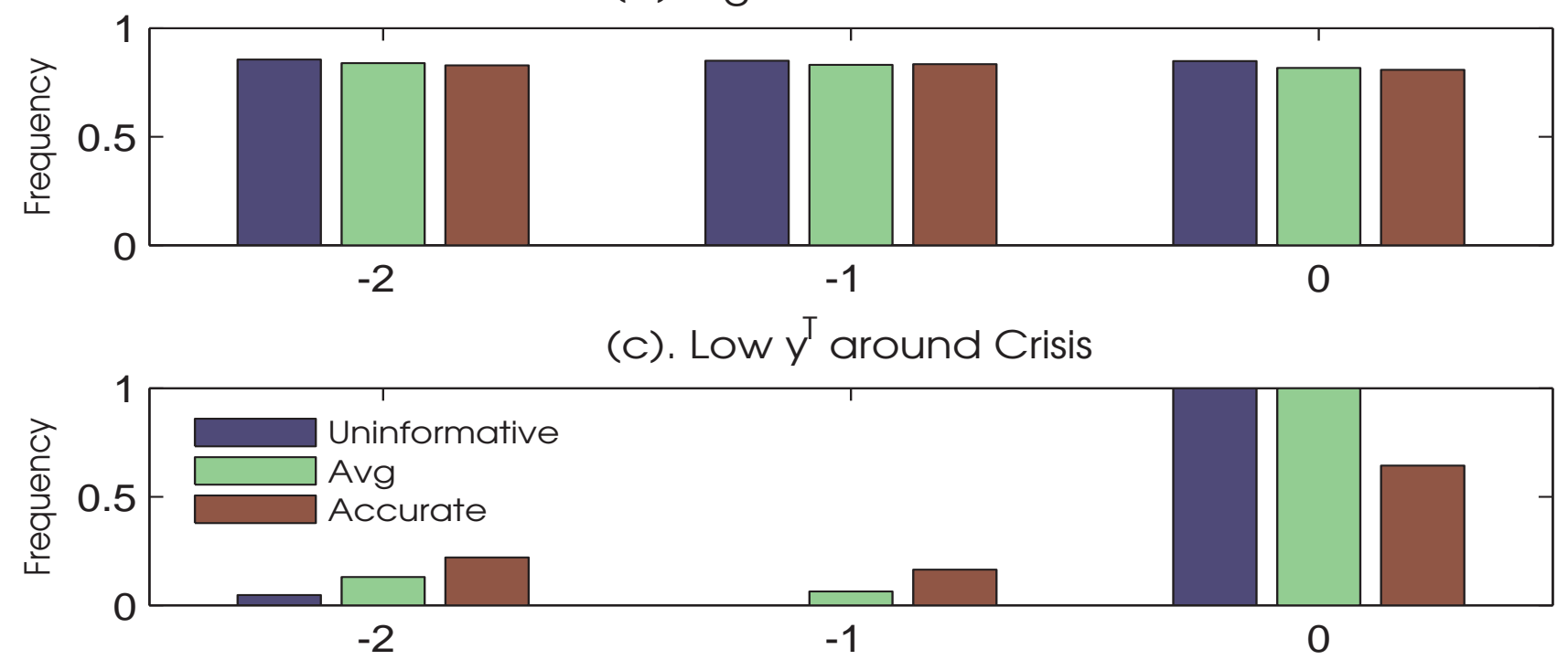

Figure 11: News Precision and Exogenous State around Crisis

\subsection{Simple Macroprudential Policies}

Given the earlier findings highlighting the complexity of the optimal policy, we compare in this section the effectiveness of alternative, simpler macroprudential policies with that of the optimal policy. In particular, we study a time- and state invariant debt tax (denoted "flat tax"), and taxes 
with a simple contingency on on the interest rate or the news signal ("R tax" and "news tax" respectively). In all cases the tax revenue is rebated to the household, and all three also feature a basic contingency setting the tax to zero if the credit constraint binds. The flat tax rate is set equal to half of the average optimal tax rate. The contingencies introduced with the $\mathrm{R}$ and news taxes are motivated by the state-dependent pattern of the optimal debt tax in Figures 5 and 6 , so that a higher tax rate is imposed in the low-R state, and in the good or bad news states. In particular, the $\mathrm{R}$ tax is set to the average optimal tax rate, twice as much as the flat tax, in the low- $R$ regime, and is set equal to the flat tax rate in the high- $R$ regime. The news tax is set to the average optimal tax rate in both good- and bad-news states, and to the flat tax rate in the average-news state.

Figure 12 the compares the ergodic distributions of bond holdings in the DE and in the three econonomies with simple macroprudential taxes. The Figure shows that the ergodic distributions of bonds shift to the right, with the flat and $\mathrm{R}$ taxes doing about the same, and the news tax showing a somewhat stronger response.

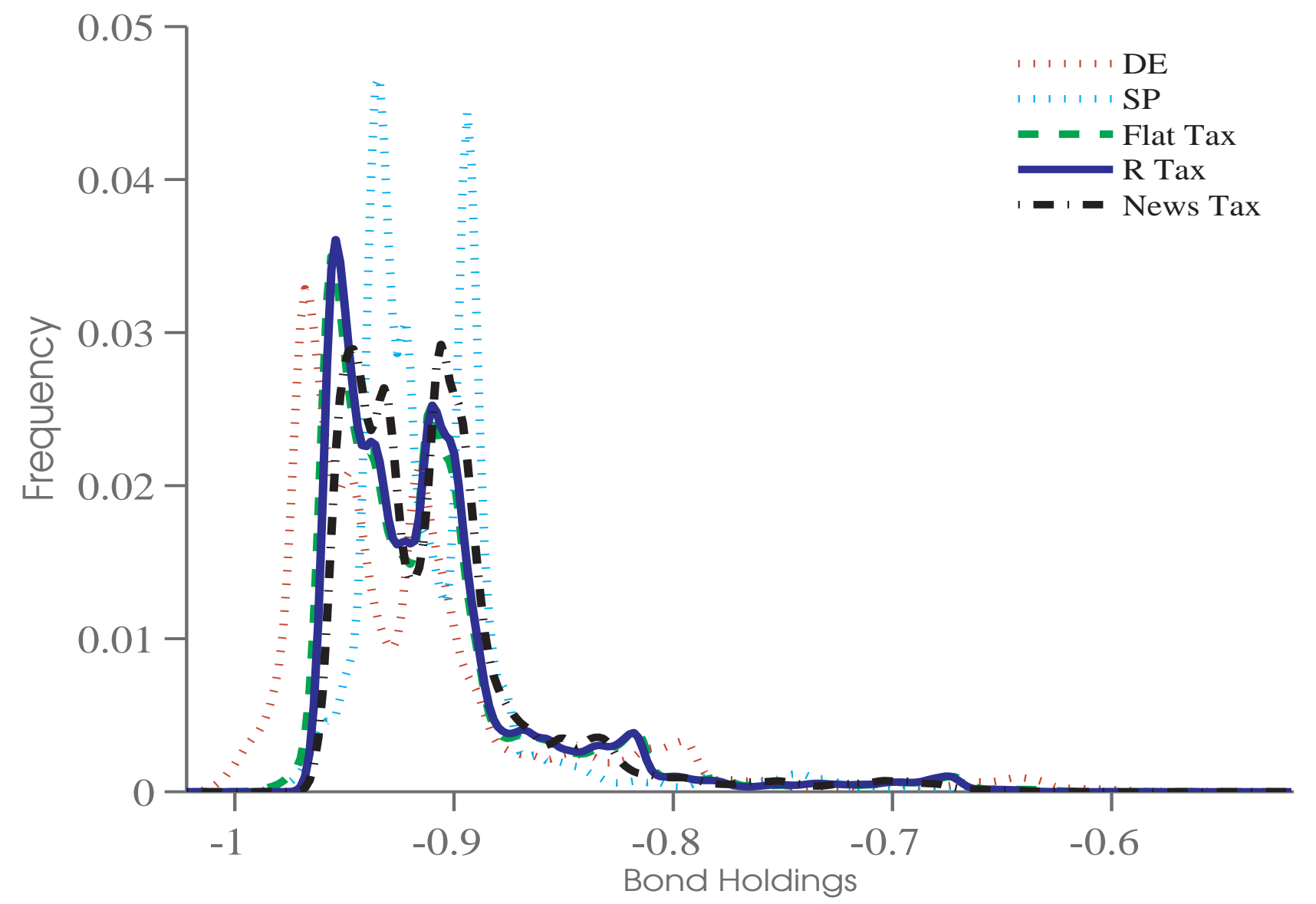

Figure 12: Ergodic Distribution of Bond Holdings

Table 3 shows that these simple policies remain somewhat effective in containing financial crises. These results are in line with Bianchi (2011) who showed that a fixed tax can achieve 
sizable gains of the optimal state contingent tax. ${ }^{15}$ What is interesting here is to notice that the news tax and the $R$ tax achieve higher gains than the flat tax, which again emphasizes the importance of adjusting policy according to the type of shocks hitting the economy.

Table 3: Comparison with Different Tax Rules

\begin{tabular}{lccccc}
\hline & $(1)$ & $(2)$ & $(3)$ & $(4)$ & $(5)$ \\
Long-run Moments & DE & SP & Flat Tax & R Tax & News Tax \\
\hline$E[B / Y] \%$ & -29.61 & -29.30 & -29.37 & -29.34 & -29.25 \\
$\sigma(C A / Y) \%$ & 3.18 & 1.76 & 2.53 & 2.43 & 2.23 \\
Welfare Gain \% & n/a & 0.117 & 0.056 & 0.063 & 0.079 \\
Prob of Crisis \% & 3.52 & 2.29 & 3.03 & 2.97 & 2.89 \\
\hline \multicolumn{5}{c}{ Financial Crisis Moments } \\
$\Delta C \%$ & -14.39 & -9.42 & -12.09 & -11.73 & -10.89 \\
$\Delta R E R \%$ & -45.56 & -27.64 & -36.43 & -35.13 & -32.27 \\
$\Delta C A / Y \%$ & 13.48 & 7.07 & 10.44 & 9.97 & 8.93 \\
\hline
\end{tabular}

\subsection{Alternative Specifications}

Table 4 shows calibration parameters for four experiments in which we changed the nature of the news being received, by changing the variable about which the signals provide information and the specification of global liquidity shocks. Table 5 shows the main moments that each experiment produces. In all four cases the Markov process of $y^{T}$ is kept as in the baseline. Panel (2), the scenario labeled $y^{T}$ news, $R$, shows the baseline results in which we have signals about $y^{T}$ and regime-switching shocks to $R$. Panel (3), labeled $y^{T}$ news, $\kappa$, changes the regime-switching process of global liquidity to shocks to $\kappa$, across the $\kappa_{L}$ and $\kappa_{H}$ values shown in the Table. Panel (1), labeled $\kappa$ news uses also regime-switching shocks in $\kappa$ but in addition it changes the signals from signals about future $y^{T}$ to signals about future $\kappa$, with a precision of 0.75 (since there are two $\kappa$ realizations, the midpoint between completely uninformative and perfectly informative signals is now 0.75). Finally, Panel (4), labeled $R$ news, moves back to the regime-switching shocks in $R$, and models the signals as being about future $R$, again with $\theta=0.75$ because $R$ has two realizations.

\footnotetext{
${ }^{15}$ In contrast, Bianchi and Mendoza (2013) studied simple macroprudential policy rules in a model in which the credit constraint uses assets as collateral and found that simple policies are much less effective than the optimal policy even when optimized to maximize welfare gains and fixed taxes can be welfare-reducing relative in a region of the state space where the collateral constraint is binding due to the depressing effect of taxes on asset prices.
} 
Table 4: Parameter Values Used for News on Different Shocks

\begin{tabular}{lcccc}
\hline & $(1)$ & $(2)$ & $(3)$ & $(4)$ \\
Parameter & $\kappa$ news, $y^{T}$ & $y^{T}$ news, $R$ & $y^{T}$ news, $\kappa$ & $R$ news, $y^{T}$ \\
\hline$y^{N}$ & 1 & 1 & 1 & 1 \\
$N_{y^{T}}$ & 4 & 3 & 3 & 5 \\
$E\left[y^{T}\right]$ & 1 & 1 & 1 & 1 \\
$\rho_{y^{T}}$ & 0.54 & 0.54 & 0.54 & 0.54 \\
$\sigma_{y^{T}}$ & 0.059 & 0.059 & 0.059 & 0.059 \\
$\beta$ & 0.91 & 0.91 & 0.91 & 0.91 \\
$\gamma$ & 2 & 2 & 2 & 2 \\
$\eta$ & 0.205 & 0.205 & 0.205 & 0.205 \\
$\kappa_{L}$ & 0.32 & 0.32 & 0.32 & 0.32 \\
$\kappa_{H}$ & 0.5 & $\mathrm{n} / \mathrm{a}$ & 0.5 & $\mathrm{n} / \mathrm{a}$ \\
$\omega$ & 0.32 & 0.32 & 0.32 & 0.32 \\
\hline News Quality & 0.75 & $\frac{2}{3}$ & $\frac{2}{3}$ & 0.75 \\
$R_{H}$ & 1.00775 & 1.0145 & 1.00775 & 1.0145 \\
$R_{L}$ & $\mathrm{n} / \mathrm{a}$ & 0.9672 & $\mathrm{n} / \mathrm{a}$ & 0.9672 \\
$F_{h h}$ & 0.9333 & 0.9333 & 0.9333 & 0.9333 \\
$F_{l l}$ & 0.6 & 0.6 & 0.6 & 0.6 \\
\hline
\end{tabular}

Table 5 shows that the effectiveness of the macroprudential policy varies markedly across the four experiments. The probability of financial crises in both the DE and SP is very different, as well as the moments that characterize financial crises and the pre-crisis mean optimal macroprudential debt tax. In terms of the reduction in the average consumption drop when a financial crisis hits, the policy is most effective in the experiments in Panels (2) and (3) with news about $y^{T}$, for which the policy has about the same effectiveness under $R$ shocks or $\kappa$ shocks, followed by the experiment of Panel (1) with news about future $\kappa$, and finally Panel (4), where the policy is least effective. Hence, these results suggest that the optimal macrorpudential policy is also likely to require variation of the policy instrument that captures the nature of the global liquidity movements (i.e. whether they are more reflected in interest rates or in tightness of credit availability) and the variables about which news provide information with different precision. 
Table 5: Model Moments for News on Different Shocks

\begin{tabular}{lcccccccc}
\hline & \multicolumn{2}{c}{$(1)$} & \multicolumn{2}{c}{$(2)$ (Baseline) } & \multicolumn{2}{c}{$(3)$} & \multicolumn{2}{c}{$(4)$} \\
Model Moment & $\kappa$ news, $y^{T}$ & \multicolumn{2}{c}{$y^{T}$ news, $R$} & $y^{T}$ news, $\kappa$ & \multicolumn{2}{c}{$R$ news, $y^{T}$} \\
\hline Long-run Moments & $\mathrm{DE}$ & $\mathrm{SP}$ & $\mathrm{DE}$ & $\mathrm{SP}$ & $\mathrm{DE}$ & $\mathrm{SP}$ & $\mathrm{DE}$ & $\mathrm{SP}$ \\
\hline$\sigma(C A / Y)(\%)$ & 3.94 & 2.64 & 3.18 & 1.75 & 3.47 & 1.97 & 3.27 & 2.64 \\
Welfare Gain (\%) & $\mathrm{n} / \mathrm{a}$ & 0.11 & $\mathrm{n} / \mathrm{a}$ & 0.12 & $\mathrm{n} / \mathrm{a}$ & 0.13 & $\mathrm{n} / \mathrm{a}$ & 0.06 \\
$E[B / Y](\%)$ & -29.72 & -29.19 & -29.62 & -29.31 & -29.84 & -29.46 & -29.31 & -29.10 \\
Prob of Crisis (\%) & 4.06 & 3.76 & 3.51 & 2.27 & 3.67 & 2.19 & 1.78 & 0.54 \\
\hline Financial Crisis Moments & & & & & & & \\
\hline$\Delta C(\%)$ & -18.46 & -13.79 & -14.39 & -9.41 & -15.36 & -10.10 & -20.21 & -17.58 \\
$\Delta R E R(\%)$ & -62.34 & -43.28 & -45.55 & -27.62 & -49.49 & -30.04 & -71.91 & -60.33 \\
$\Delta C A / Y(\%)$ & 17.68 & 11.24 & 13.47 & 7.06 & 14.74 & 7.85 & 19.28 & 15.62 \\
$E[\tau]$ pre-crisis (\%) & $\mathrm{n} / \mathrm{a}$ & 6.52 & $\mathrm{n} / \mathrm{a}$ & 4.65 & $\mathrm{n} / \mathrm{a}$ & 5.27 & $\mathrm{n} / \mathrm{a}$ & 5.21 \\
\hline Switch from High Liquidity to Low Liquidity & & & & & \\
\hline$\Delta C(\%)$ & -21.31 & -15.97 & -15.49 & -10.18 & -14.45 & -9.27 & -18.67 & -16.48 \\
$\Delta R E R(\%)$ & -76.42 & -52.82 & -49.93 & -30.25 & -46.42 & -27.59 & -65.38 & -55.82 \\
$\Delta C A / Y(\%)$ & 21.87 & 14.28 & 14.65 & 7.70 & 13.62 & 6.94 & 17.26 & 14.21 \\
$E[\tau]$ pre-crisis (\%) & $\mathrm{n} / \mathrm{a}$ & 7.82 & $\mathrm{n} / \mathrm{a}$ & 5.11 & $\mathrm{n} / \mathrm{a}$ & 7.01 & $\mathrm{n} / \mathrm{a}$ & 5.40 \\
\hline
\end{tabular}

\section{Conclusions}

This paper introduced news about future income and regime switches in global liquidity to a Fisherian model of financial crises and macroprudential policy. Quantitative results from an experiment calibrated using data for Argentina show that both news shocks and global liquidity regimes have important effects on the Fisherian financial amplification mechanism: First, good news and low interest rates fuel credit booms, resulting in severe financial crises when good shocks are not realized and when there is a sudden shift in financial regimes. Second, when the precision of news increase, agents accumulate less precautionary savings leading to less frequent but more severe financial crises. Third, macroprudential debt taxes are effective tools for reducing both the frequency and magnitude of financial crises, but the results show the need for significant variation of optimal debt taxes when news are good v. bad, and when the regime of global liquidity shifts.

The findings of this paper illustrate the importance of considering unconventional sources of financial instability, such as news about future economic fundamentals and regime-switches in global liquidity, in financial crises dynamics and in the design and evaluation of macroprudential policies. 


\section{References}

Akinci, O. and Chahrour, R. (2014). 'Good News is Bad News: Leverage Cycles and Sudden Stops'. Mimeo, Boston College Department of Economics.

Beaudry, P. and Portier, F. (2006). 'Stock prices, news, and economic fluctuations'. The American economic review, vol. 96, no. 4, 1293-1307.

Beaudry, P. and Portier, F. (2014). 'News-Driven Business Cycles: Insights and Challenges'. Journal of Economic Literature, vol. 52, no. 4, 993-1074.

Bengui, J. and Bianchi, J. (2014). 'Capital Flow Management when Capital Controls Leak'. Mimeo, University of Montreal.

Benigno, G., Chen, H., Otrok, C., Rebucci, A., and Young, E. R. (2013). 'Financial crises and macro-prudential policies'. Journal of International Economics, vol. 89, no. 2, 453-470.

Benigno, G., Chen, H., Otrok, C., Rebucci, A., and Young, E. R. (2014). 'Capital Controls or Exchange Rate Policy? A Pecuniary Externality Perspective'. Mimeo, LSE.

Bianchi, J. (2011). 'Overborrowing and Systemic Externalities in the Business Cycle'. American Economic Review, vol. 101, no. 7, 3400-3426.

Bianchi, J., Boz, E., and Mendoza, E. G. (2012). 'Macroprudential Policy in a Fisherian Model of Financial Innovation'. IMF Economic Review, vol. 60, no. 2, 223-269.

Bianchi, J. and Mendoza, E. G. (2010). 'Overborrowing, Financial Crises and 'Macroprudential' Policy'. NBER Working Paper No. 16091.

Bianchi, J. and Mendoza, E. G. (2013). 'Optimal Time-Consistent Macroprudential Policy'. NBER Working Paper No 19704.

Blanchard, O. J., L'Huillier, J.-P., and Lorenzoni, G. (2013). 'News, Noise, and Fluctuations: An Empirical Exploration'. The American Economic Review, vol. 103, no. 7, 3045-3070.

Borio, C. (2014). 'The financial cycle and macroeconomics: What have we learnt?' Journal of Banking \& Finance, vol. 45, 182-198.

Boz, E. and Mendoza, E. G. (2014). 'Financial innovation, the discovery of risk, and the US credit crisis'. Journal of Monetary Economics, vol. 62, 1-22.

Bruno, V. and Shin, H. S. (2014). 'Cross-Border Banking and Global Liquidity*'. The Review of Economic Studies, page rdu042. 
Calvo, G. A., Leiderman, L., and Reinhart, C. M. (1996). 'Inflows of Capital to Developing Countries in the 1990s'. The Journal of Economic Perspectives, pages 123-139.

Christiano, L., Ilut, C. L., Motto, R., and Rostagno, M. (2010). 'Monetary policy and stock market booms'. NBER Working Paper No 16402.

Durdu, C. B., Nunes, R., and Sapriza, H. (2013). 'News and sovereign default risk in small open economies'. Journal of International Economics, vol. 91, no. 1, 1-17.

Farhi, E. and Werning, I. (2012). 'Dealing with the trilemma: Optimal capital controls with fixed exchange rates'. NBER Working Paper No 18199.

Flemming, J., L'Huillier, J.-P., and Piguillem, F. (2015). 'The Optimal Tradeoff Between Consumption Smoothing and Macroprudential Regulation'. Mimeo, EIEF.

Galati, G. and Moessner, R. (2013). 'Macroprudential policy-a literature review'. Journal of Economic Surveys, vol. 27, no. 5, 846-878.

Galati, G. and Moessner, R. (2014). 'What do we know about the effects of macroprudential policy?' Mimeo, De Nederlandsche Bank Working Paper.

Jaimovich, N. and Rebelo, S. (2009). 'Can News about the Future Drive the Business Cycle?' The American economic review, vol. 99, no. 4, 1097-1118.

Jeanne, O. and Korinek, A. (2010). 'Managing Credit Booms and Busts: A Pigouvian Taxation Approach'. NBER Working Paper No 16377.

Korinek, A. and Mendoza, E. G. (2014). 'From Sudden Stops to Fisherian Deflation: Quantitative Theory and Policy Implications'. Annual Review of Economics, vol. 6, no. 1.

Lane, P. and Milesi-Ferretti, G. (2001). 'The external wealth of nations: measures of foreign assets and liabilities for industrial and developing countries'. Journal of international Economics, vol. 55, no. 2, 263-294.

Mendoza, E. G. (2002). 'Credit, Prices, and Crashes: Business Cycles with a Sudden Stop'. In 'Preventing Currency Crises in Emerging Markets', Frankel, Jeffrey and Sebastian Edwards eds. Chicago: University of Chicago Press.

Mendoza, E. G. (2010). 'Sudden Stops, Financial Crises, and Leverage'. The American Economic Review, vol. 100, no. 5, 1941-1966.

Mendoza, E. G. and Terrones, M. E. (2012). 'An anatomy of credit booms and their demise'. NBER Working Paper No 18379. 
Reinhart, C. M. and Rogoff, K. S. (2014). 'Recovery from Financial Crises: Evidence from 100 Episodes'. The American Economic Review, vol. 104, no. 5, 50-55.

Schmitt-Grohé, S. and Uribe, M. (2012). 'What's news in business cycles'. Econometrica, vol. 80, no. $6,2733-2764$.

Schmitt-Grohé, S. and Uribe, M. (2013). 'Downward nominal wage rigidity, currency pegs, and involuntary unemployment'. Mimeo, Columbia University.

Schularick, M. and Taylor, A. M. (2012). 'Credit Booms Gone Bust: Monetary Policy, Leverage Cycles, and Financial Crises, 1870-2008'. The American Economic Review, vol. 102, no. 2, 1029.

Shin, H. S. (2013). 'The Second Phase of Global Liquidity and Its Impact on Emerging Economies'. Mimeo, Princeton University.

Stein, J. C. (2012). 'Monetary policy as financial stability regulation'. The Quarterly Journal of Economics, vol. 127, no. 1, 57-95. 


\section{Appendix: Solution Method}

The Matlab code named "Model.m" provides the algorithm for solving the model. The code is divided in six sections.

Section 1. Parameter Values sets the parameters values shown in table 1. We use 100 points in the grid for bonds and three states for $y^{T}$ shocks, three states for news shocks and two states for interest rates shocks. The convergence tolerance level for the solution of decision rules, as defined in Section 3 below, is set to $\epsilon=1 e^{-5}$.

Section 2. Construction of Markov Chain discretizes $y^{T}$ shocks using Tauchen and Hussey's method. The time-series properties of the $y^{T}$ process that the method targets are estimates obtained by Bianchi (2011)using data for Argentina, and the corresponding moments are reported in table 1. We incorporate news shocks according to the formulae in the Section 2.3 of the paper. Then we add global liquidity shocks to construct the entire transition matrix, assuming $y^{T}$ shocks and global liquidity shocks are independent.

Section 3. Decentralized Equilibrium solves the decentralized equilibrium using the timeiteration method. Intuitively, this algorithm solves the model by backward recursive-substitution of the model's optimality conditions written in recursive form. In particular, the algorithm solves for the recursive functions $c^{T}(b, z), P^{N}(b, z)$ and $B(b, z)$ that satisfy these four conditions:

$$
\begin{aligned}
P^{N}(b, z) & =\frac{1-\omega}{\omega}\left(\frac{c^{T}(b, z)}{y^{N}}\right)^{1+\eta} \\
u_{T}\left(c^{T}(b, z), y^{N}\right) & \geq \beta R(z) E_{z}\left[u_{T}\left(c^{T}\left(B(b, z), z^{\prime}\right), y^{N}\right)\right] \\
B(b, z) & \geq-\kappa R(z)\left(P^{N}(b, z) y^{N}+y^{T}(z)\right) \\
c^{T}(b, z)+q(z) B(b, z) & =b+y^{T}(z)
\end{aligned}
$$

where $z$ is a triple $\left(y^{T}, q, s\right)$ that includes the realizations of the exogenous shocks to $y^{T}$, the news signal s, and $q$ (recall that $q=\frac{1}{R}$ ).

Start the algorithm at an initial point defined by setting $K=1$ and define conjectures for the equilibrium functions at this point, denoted $c_{K}^{T}(b, z), p_{K}^{N}(b, z)$ and $B_{K}(b, z)$. Then proceed with the following steps:

1. Set $B_{K+1}(b, z)=-\kappa R(z)\left(P_{K}^{N}(b, z) y^{N}+y^{T}(z)\right)$, and calculate $c_{K+1}^{T}(b, z)$ using equation 27 , which yields $c_{K+1}^{T}(b, z)=b+y^{T}(z)-(1 / R(z)) B_{K+1}(b, z)$

2. Compute

$$
U \equiv u_{T}\left(c_{K+1}^{T}(b, z), y^{N}\right)-\beta R(z) E_{z}\left[u_{T}\left(c_{K}^{T}\left(B_{K}(b, z), z^{\prime}\right), y^{N}\right)\right]
$$

3. If $U>0$, the collateral constraint binds and then equation 24 implies that the equilibrium 
price must be given by $p_{K+1}^{N}(b, z)=\frac{1-\omega}{\omega}\left(\frac{c_{K+1}^{T}(b, z)}{y^{N}}\right)^{1+\eta}$

4. If $U \leq 0$, the collateral constraint does not bind. Discard the values of $B_{K+1}(b, z)$ and $C_{K+1}^{T}(b, z)$ set in Step 1 , and solve for $c_{K+1}^{T}(b, z)$ as the recursive function that satisfies the Euler equation 25 with equality using the fsolve root-finding routine. We then compute $P_{K+1}^{N}(b, z)$ using again equation 24 and $B_{K+1}(b, z)$ using equation 27

5. The above steps will in general produce a new set of functions $c_{K+1}^{T}(b, z), p_{K+1}^{N}(b, z)$ and $B_{K+1}(b, z)$ that will differ from the conjectures $c_{K}^{T}(b, z), p_{K}^{N}(b, z)$ and $B_{K}(b, z)$. We thus check the convergence criterion $\sup \left|x_{K+1}-x_{K}\right| \leq \epsilon$ for $x=B, c^{T}, p^{N}$. If the criterion fails, the conjectures are replaced with the solutions $c_{K+1}^{T}(b, z), p_{K+1}^{N}(b, z)$ and $B_{K+1}(b, z)$ and the procedure returns to step 1 using these new conjectures. If the convergence criterion $\sup \left|x_{K+1}-x_{K}\right| \leq \epsilon$ holds, the recursive functions are a solution to the decentralized competitive equilibrium in recursive form.

Section 4. Social Planner solves the social planer's problem. The algorithm is also a timeiteration code similar to that of decentralized equilibrium. The difference is that $u_{T}$ in equation 25 becomes

$$
u_{T}^{S P}=u_{T}+\mu^{S P} \psi
$$

where $\mu^{S P} \geq 0$, with strict inequality if the collateral constraint 26 binds, and $\psi$ is the externality term given by $\kappa(\eta+1)\left(\frac{1-\omega}{\omega}\right)\left(\frac{c^{T}}{y^{N}}\right)^{\eta}$.

Section 5. Welfare Calculation takes the optimal policy functions we derived from section 3 and 4 of the Matlab code, and iterates until convergence to get value functions of the private agent and social planer. We then calculate the welfare gain as in Bianchi (2011).

Section 6. Optimal Tax calculates optimal macro-prudential tax according to equation 23, and set tax rate to zero when the borrowing constraint binds.

The Matlab code named "Simulation.m" simulate our model. The code is divided in three sections.

Section 1. Simulation simulates our model for 201,000 periods. The first 1,000 periods are discarded to eliminate initial condition dependence. The initial bond position is set as mid point of the bond grid for both DE and SP economies.

Section 2. Event Analysis identifies sudden stop events, and find the surrounding three periods before and after the event. Crisis is defined as current account goes beyond two standard deviation and collateral constraint binds in the decentralized economy. The crisis moments are obtained by taking average across all crisis episodes.

Section 3. Crisis Breakdown analyzes crises effects preceded by different news (see figure 5) and by different liquidity regimes (see figure 6). The definition of the breakdowns can be found in section 4.3 . 
The Matlab code "figures.m" generates figures 2, 3, 4,5, 6, 8 and 9 presented in the paper, and display table 2 in the command window. 
Dear Mick,

We are sending you the revised version of our paper "Fundamental News, Global Liquidity and Macroprudential Policy." Following your comments and those from the referees we revised the paper and made several changes. The bulleted list below summarizes the changes we made.

We hope that you and the referees are pleased with this new version of the paper.

Best regards

- Rewrote the description about the mechanism by which noisy news and regime affect the financial amplification mechanism and the design of macroprudential policy. We clarified how the analytical section of the paper highlights this and the manner in which the quantitative section provides an illustration of that mechanism.

$\bullet$

- We added a short discussion in section 4.6 of new results examining the effects of simpler macroprudential tax rules and taxes that respond to the interest rates or the noisy news, and how they compare with those of the optimal policy (this was done to address comment \# 1 from the referee report).

- We rewrote the discussion of how the precision of news affects the effectiveness of macroprudential policy, to clarify the differential effects in terms of the smaller welfare gain and average optimal tax at higher precision v. weakening effects in terms of the reduction in the crisis probability and $v$. relatively small changes in the size of the crisis impact effects on real variables. (this was in response to comment \#2 in the referee report).

- On the calibration, we emphasize that we do not take a stance of what is the most empirically plausible value for the signal precision and instead look at the entire theoretical range. The referee has specific comments on calibration. On the issue of normalization of tradable output and non-tradable output, we clarify this in footnote 9 that this is without loss of generality. Another comment of the referee is that we do not include shocks to non-tradables. We have examined this in some of our earlier work (Bianchi, 2011) and it does not generate significant differences. Given that we're including other shocks, we leave aside shocks to non-tradables for tractability reasons. 
- With regard to Comment \#4, we added in Section 4.4 a discussion of the opposing forces that affect the non-monotonicity result. When we have bad news, the possibility of future tighter constraint calls for higher tax. When we have good news, higher taxes are called for because agent borrows more. So higher taxes under two types of news come from two different channels.

- In response to comments \#5 and \#6, please note that $\theta=0.33$ is the case in which news are completely uninformative, so the model is equivalent to one without news. There were some subtle numerical issues for values of $\theta$ close to one, which we have now resolved.

- They typos in comments 7-9 were all corrected. 